\title{
STUDIES ON ANTIVIRAL AGENTS
}

\section{SYNTHESIS AND IN VITRO ANTIVIRAL ACTIVITY \\ OF 1 - $N$-HIGHER-ACYL-3"- $N$-FUNCTIONALIZED ACYLKANAMYCIN A DERIVATIVES}

\author{
Keiji Matsuda, Nobuyoshi Yasuda, Hideo Tsutsumi \\ and TAKAO TAKAYA* \\ Central Research Laboratories, Fujisawa Pharmaceutical Co., Ltd., \\ 2-1-6 Kashima, Yodogawa-ku, Osaka 532, Japan \\ (Received for publication July 20, 1985)
}

\begin{abstract}
The synthesis and antiviral activity of $1-\mathrm{N}$-palmitoyl- or $1-\mathrm{N}$-(3-hydroxytetradecanoyl)kanamycin A derivatives $(\mathbf{7}, 8)$ having various type of acyl substituents at the $N-3^{\prime \prime}$ position were investigated. The structure-activity relationships between the antiviral activity and the substituent at the $N-3^{\prime \prime}$ position is described. In this series, $3^{\prime \prime}-N$-acetyl-1-N-palmitoylkanamycin A (7c) showed the excellent antiviral activity against HSV-I and influenza virus. Further, we examined the synthesis and the antiviral activity of $3^{\prime \prime}-N$-glycylkanamycin $\mathrm{A}$ derivatives (9) having a higher-acyl group at the $N-1$ position. The $3^{\prime \prime}-N$-glycyl-1-N-pentadecanoylkanamycin A (9a) also exhibited excellent antiviral activity.
\end{abstract}

In the previous papers ${ }^{1,2)}$, we have first reported that the $1-N$-acyl- $3^{\prime \prime}-N$-trifluoroacetylkanamycin A derivatives had the strong antiviral activity against herpes simplex virus type I (HSV-I) and influenza virus, and have described the structure-activity relationships between the antiviral activity and alkyl chain length in an acyl group at the $N-1$ position. 3" $N$-Trifluoroacetylkanamycin A derivatives having a higher-acyl group, such as palmitoyl, pentadecanoyl, or hexadecanyloxycarbonyl, were found to have excellent antiviral activity against both HSV-I ( $\left.\operatorname{ID}_{50} 1.0 \sim 1.4 \mu \mathrm{g} / \mathrm{ml}\right)$ and influenza virus $\left(\mathrm{ID}_{50}\right.$ $5.6 \sim 22 \mu \mathrm{g} / \mathrm{ml})$. We have also suggested that the introduction of a higher-acyl group in the kanamycin A molecule was essential for strong antiviral activity. While, 1- $N$-higher-acyl-3"- $N$-trifluoroacetylkanamycin A derivatives ${ }^{1)}$ exhibited excellent antiviral activity. They were very soluble in water under acidic condition $(\mathrm{pH}<5.8)$, but were slightly soluble in water $(0.1 \mathrm{mg} / \mathrm{ml})$ at around neutral $\mathrm{pH}$. Based on these facts, we felt that the 1- $N$-higher-acylkanamycin A derivatives bearing various acyl groups in place of the trifluoroacetyl radical at the $N-3^{\prime \prime}$ position might improve the activity over that of 1-N-palmitoyl-3" $3^{\prime \prime} N$-trifluoroacetylkanamycin A (7u). Furthermore, the 1-Nhigher-acylkanamycin A derivatives having a functionalized acyl group, such as amino group and/or hydroxyl group, at the $\mathrm{N}-3^{\prime \prime}$ position could be soluble in water at neutral $\mathrm{pH}$.

In this paper, we report the synthesis and antiviral activity of the 1- $N$-higher-acylkanamycin $\mathrm{A}$ derivatives $(7,8,9)$ having a variety of acyl group at the $N-3^{\prime \prime}$ position.

\section{Chemistry}

We synthesized $1-N$-higher-acyl-3"- $N$-functionalized acylkanamycin A derivatives $(7,8,9)$ as follows (Schemes 1 and 2).

Protection of two amino groups at the C-3 and C-6' positions of kanamycin A (1) by reaction with $\mathrm{N}$-benzyloxycarbonyloxy-5-norbornene-2,3-dicarboximide, followed by regiospecific $3^{\prime \prime}$-amino 
Scheme 1. Synthesis of 1-N-acyl-3"'-N-functionalized acylkanamycin A derivatives $(7,8,9)$.

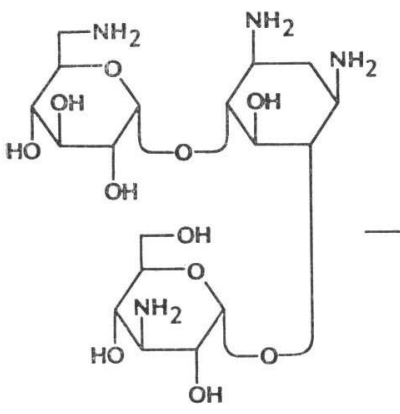

Kanamycin A (B)

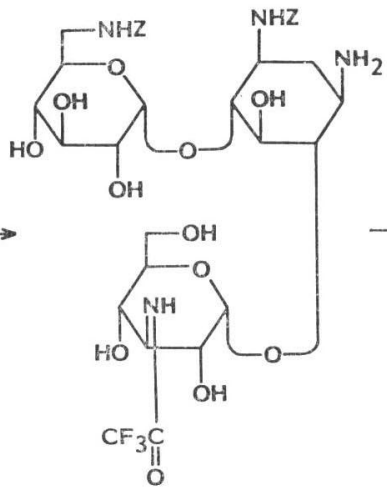

2

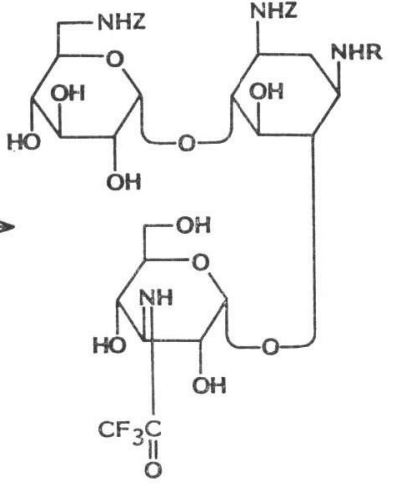

3
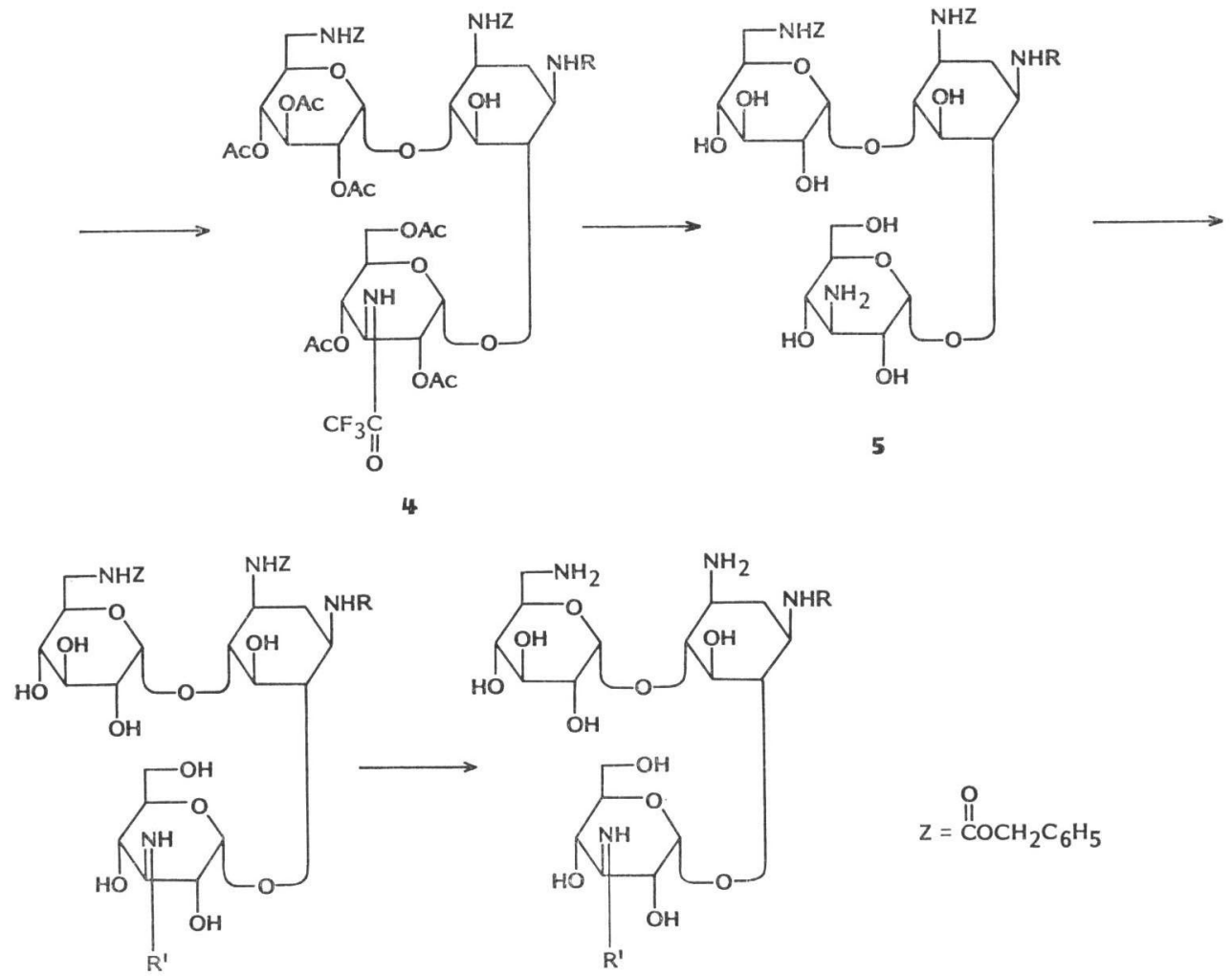

6

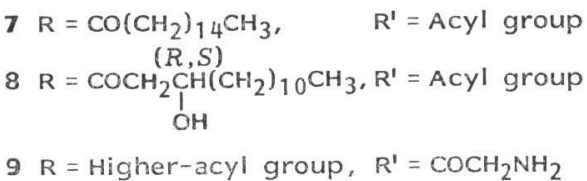

protection with ethyl trifluoroacetate, gave 3,6'-bis- $N$-benzyloxycarbonyl- $3^{\prime \prime}-N$-trifluoroacetylkanamycin A (2) by using the method of TsuchiYA et al. ${ }^{3)}$. Acylation of 2 with an acyl chloride or an activated ester gave the corresponding $1-N$-acyl-3, $6^{\prime}$-bis( $N$-benzyloxycarbonyl)- $3^{\prime \prime}-N$-trifluoroacetylkanamycin 
Scheme 2. Synthesis of 1- $N$-acyl-3"'- $N$-functionalized acylkanamycin A derivatives (7c, k, o, 8c, 9b, c).

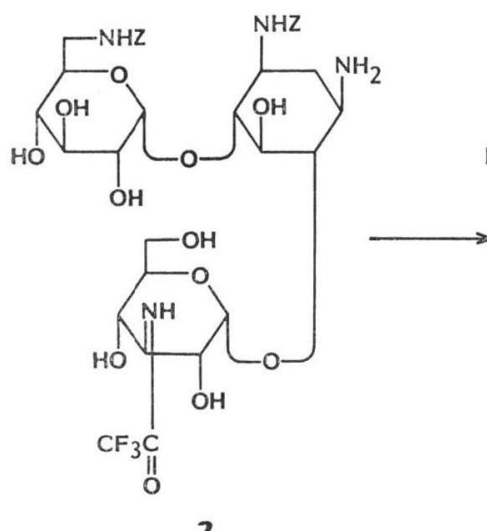

2

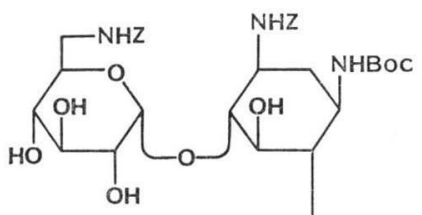

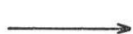

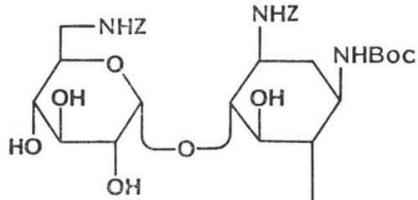<smiles>[R]C1C(O)C(CO)OC(COCCO)C1O</smiles>

10

11a $\mathrm{R}^{\prime}=\mathrm{COCH}_{2} \mathrm{NHZ}$

11 b $\mathrm{R}^{\prime}=\mathrm{COCH}_{2} \mathrm{OCH}_{2} \mathrm{C}_{6} \mathrm{H}_{5}$ $11 \mathrm{c} \mathrm{R}^{\prime}=\mathrm{COCH}_{3}$
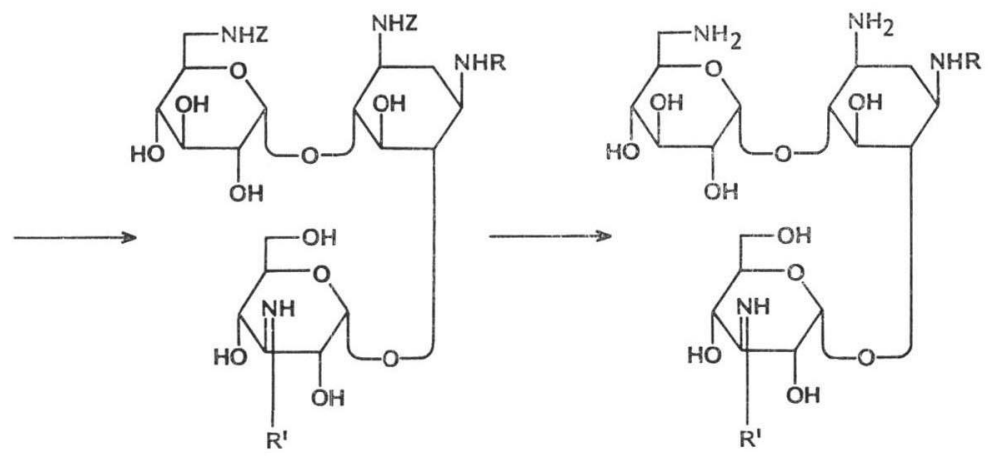

$$
\begin{aligned}
& \mathrm{Z}=\stackrel{\mathrm{O}}{\mathrm{COCH}} \mathrm{C}_{2} \mathrm{C}_{6} \mathrm{H}_{5} \\
& \mathrm{BOC}=\stackrel{\mathrm{COC}\left(\mathrm{CH}_{3}\right)_{3}}{\mathrm{O}}
\end{aligned}
$$

6

A derivatives (3) as reported in the previous paper ${ }^{22}$. Physical data and yields of $\mathbf{3}$ are summarized in Table 1. Removal of the trifluoroacetyl group of 3 under alkaline condition $\left(1 \mathrm{M} \mathrm{NH}_{4} \mathrm{OH}\right.$ - aqueous THF or $\mathrm{KOH}-\mathrm{MeOH}$ ) was unsuccessful, because steric hindrance of the higher-acyl group at the $N-1$ position might prevent hydroxide anion from attacking the trifluoroacetyl group at the $N-3^{\prime \prime}$ position. Therefore, we assumed that acetylation of the hydroxyl groups in $\mathbf{3}$ could overcome this steric hindrance by changing the conformation of 3 . Acetylation of 3 with acetic anhydride gave the corresponding $2^{\prime}, 3^{\prime}, 4^{\prime}, 2^{\prime \prime}, 4^{\prime \prime}, 6^{\prime \prime}$-hexa- $O$-acetyl-1- $N$-acyl-3, 6'-bis( $N$-benzyloxycarbonyl)-3'" $N$-trifluoroacetylkanamycin A derivatives (4), (Table 2). Treatment of 4 with a solution of $\mathrm{KOH}$ in methanol afforded the 1- $N$-acyl-3, $6^{\prime}$-bis( $N$-benzyloxycarbonyl)kanamycin A derivatives (5) in good yield (Table $3)$. Acylation of 5 with an acyl chloride or an activated ester gave the 1-N-acyl-3,6'-bis( $N$-benzyloxycarbonyl)- $3^{\prime \prime}-N$-acylkanamycin A derivatives (6) as a solid (Tables 4, 5 and 6). Finally, hydrogenation of 6 with $10 \%$ palladium on carbon, followed by lyophilization afforded the corresponding $1-N$-acyl$3^{\prime \prime}-\mathrm{N}$-functionalized acylkanamycin A di- or trihydrochloride $(\mathbf{7}, \mathbf{8}, \mathbf{9})$ as a hygroscopic solid (Tables 7, 8 and 9).

On the other hand, reaction of 2 with 2-(tert-butoxycarbonyloximino)-2-phenylacetonitrile in 
Table 1. Physical data and yields of $1-N$-higher-acyl-3,6'-bis( $N$-benzyloxycarbonyl)- $3^{\prime \prime}-N$-trifluoroacetylkanamycin A derivatives (3).

\begin{tabular}{|c|c|c|c|c|c|}
\hline No. & $\mathrm{R}$ & $\begin{array}{l}\text { Yield } \\
(\%)\end{array}$ & $\begin{array}{c}\mathrm{MP} \\
\left({ }^{\circ} \mathrm{C}, \mathrm{dec}\right)\end{array}$ & IR (Nujol, $\mathrm{cm}^{-1}$ ) & NMR (DMSO- $\left.d_{6}, \delta\right)$ \\
\hline $3 a$ & $\mathrm{CO}\left(\mathrm{CH}_{2}\right)_{13} \mathrm{CH}_{3}$ & 84 & 284 & $\begin{array}{l}1690,1640,1530 \\
1260\end{array}$ & $\begin{array}{l}0.93\left(3 \mathrm{H}, \mathrm{m}, \mathrm{CH}_{3}\right), \\
1.07\left(24 \mathrm{H}, \mathrm{s}, \mathrm{CH}_{2}\right)\end{array}$ \\
\hline $3 b$ & $\mathrm{CO}\left(\mathrm{CH}_{2}\right)_{14} \mathrm{CH}_{3}$ & 92 & 270 & $\begin{array}{l}1690 \sim 1680,1530, \\
1040 \sim 1010\end{array}$ & \\
\hline $3 c$ & $\begin{array}{c}(R, S) \\
\mathrm{COCH}_{2} \mathrm{CH}\left(\mathrm{CH}_{2}\right)_{6} \mathrm{CH}_{3} \\
\text { OAc }\end{array}$ & 69 & 283 & $1705,1540,1055$ & $\begin{array}{l}0.90\left(3 \mathrm{H}, \mathrm{m}, \mathrm{CH}_{3}\right), \\
1.93\left(3 \mathrm{H}, \mathrm{s}, \mathrm{CH}_{3} \mathrm{CO}\right)\end{array}$ \\
\hline $3 d$ & $\begin{array}{c}(R, S) \\
\mathrm{COCH}_{2} \mathrm{CH}\left(\mathrm{CH}_{2}\right)_{10} \mathrm{CH}_{3} \\
\text { OAc }\end{array}$ & 74 & 265 & $\begin{array}{l}1690,1640,1540, \\
1270\end{array}$ & $\begin{array}{l}0.88\left(3 \mathrm{H}, \mathrm{m}, \mathrm{CH}_{3}\right) \\
1.22\left(20 \mathrm{H}, \mathrm{s}, \mathrm{CH}_{2}\right) \\
1.92\left(3 \mathrm{H}, \mathrm{s}, \mathrm{CH}_{3} \mathrm{CO}\right)\end{array}$ \\
\hline $3 e$ & $\underset{\mathrm{COCH}_{2} \mathrm{CH}}{(\mathrm{R}}\left(\mathrm{CH}_{2}\right)_{12} \mathrm{CH}_{3}$ & 66 & $-^{\mathrm{a}}$ & & $\begin{array}{l}0.91\left(3 \mathrm{H}, \mathrm{m}, \mathrm{CH}_{3}\right) \\
1.95\left(3 \mathrm{H}, \mathrm{s}, \mathrm{CH}_{3} \mathrm{CO}\right)\end{array}$ \\
\hline $3 f$ & $\begin{array}{c}\mathrm{OAc} \\
(R, S) \\
\mathrm{COCH}_{2} \mathrm{CH}\left(\mathrm{CH}_{2}\right)_{14} \mathrm{CH}_{3} \\
\text { OAc }\end{array}$ & 77 & 272 & $1690,1540,1170$ & $\begin{array}{l}0.90\left(3 \mathrm{H}, \mathrm{m}, \mathrm{CH}_{3}\right), \\
1.90\left(3 \mathrm{H}, \mathrm{s}, \mathrm{CH}_{3} \mathrm{CO}\right)\end{array}$ \\
\hline
\end{tabular}

a Not measured.

Table 2. Physical data and yields of $2^{\prime}, 3^{\prime}, 4^{\prime}, 2^{\prime \prime}, 4^{\prime \prime}, 6^{\prime \prime}$-hexa- $O$-acetyl-1- $N$-acyl-3,6'-bis $(N$-benzyloxycarbonyl)-3"- $N$-trifluoroacetylkanamycin A derivatives (4).

\begin{tabular}{|c|c|c|c|c|}
\hline No. & $\mathrm{R}$ & $\begin{array}{l}\text { Yield } \\
(\%)\end{array}$ & IR (Nujol, $\mathrm{cm}^{-1}$ ) & $\operatorname{NMR}\left(\mathrm{CDCl}_{3}, \delta\right)$ \\
\hline $4 a$ & $\mathrm{CO}\left(\mathrm{CH}_{2}\right)_{13} \mathrm{CH}_{3}$ & 98 & $\begin{array}{l}1745,1720,1690,1640 \\
1530\end{array}$ & $\begin{array}{l}0.92\left(3 \mathrm{H}, \mathrm{m}, \mathrm{CH}_{3}\right) \\
1.90 \sim 2.15\left(18 \mathrm{H}, \mathrm{CH}_{3} \mathrm{CO}\right)\end{array}$ \\
\hline $4 b$ & $\mathrm{CO}\left(\mathrm{CH}_{2}\right)_{14} \mathrm{CH}_{3}$ & 100 & & $\begin{array}{l}0.93\left(3 \mathrm{H}, \mathrm{m}, \mathrm{CH}_{3}\right) \\
1.28\left(26 \mathrm{H}, \mathrm{s}, \mathrm{CH}_{2}\right)\end{array}$ \\
\hline $4 c$ & $\begin{array}{c}(R, S) \\
\mathrm{COCH}_{2} \mathrm{CH}\left(\mathrm{CH}_{2}\right)_{8} \mathrm{CH}_{3} \\
\text { OAc } \\
\text { OAc } \\
(R, S)\end{array}$ & 89 & $1750,1645,1230,1150$ & $0.95\left(3 \mathrm{H}, \mathrm{m}, \mathrm{CH}_{3}\right)$ \\
\hline $4 d$ & $\underset{\text { OAc }}{\mathrm{COCH}_{2} \mathrm{CH}\left(\mathrm{CH}_{2}\right)_{12} \mathrm{CH}_{3}}$ & 76 & $\begin{array}{l}1740,1700,1640,1540, \\
1260\end{array}$ & $0.95\left(3 \mathrm{H}, \mathrm{m}, \mathrm{CH}_{3}\right)$ \\
\hline $4 e$ & $\begin{array}{c}(R, S) \\
\mathrm{COCH}_{2} \mathrm{CH}\left(\mathrm{CH}_{2}\right)_{14} \mathrm{CH}_{3} \\
\text { OAc }\end{array}$ & 100 & $\begin{array}{l}1740,1650,1540,1230 \\
1150\end{array}$ & $0.93\left(3 \mathrm{H}, \mathrm{m}, \mathrm{CH}_{3}\right)$ \\
\hline
\end{tabular}

aqueous THF, followed by removal of trifluoroacetyl group at the $N-3^{\prime \prime}$ position with a mixture of conc $\mathrm{NH}_{4} \mathrm{OH}$ and DMF gave the desired 3,6'-bis( $N$-benzyloxycarbonyl)-1- $N$-(tert-butoxycarbonyl)kanamycin A (10). In this procedure, removal of trifluoroacetyl group at the $N-3^{\prime \prime}$ position was smoothly carried out under alkaline condition. Acylation at the $N-3^{\prime \prime}$ position with $N$-(benzyloxycarbonyl)glycine, benzyloxyacetic acid, or acetic acid afforded the 3,6'-bis( $N$-benzyloxycarbonyl)-1- $N$-(tertbutoxycarbonyl)-3"- $N$-( $N$-benzyloxycarbonylglycyl)-, $-3^{\prime \prime}-N$-(benzyloxyacetyl)-, or $-3^{\prime \prime}-N$-acetylkanamycin A (11a, b, c). Treatment of $\mathbf{1 1}$ with trifluoroacetic acid and anisole, followed by acylation at the $N$-1 position with a higher-acyl chloride gave the $1-N$-acyl-3, $6^{\prime}$-bis $\left(N\right.$-benzyloxycarbonyl)- $3^{\prime \prime}-N$ functionalized acylkanamycin A derivatives (6) (Tables 4, 5 and 6). Finally, hydrogenation with $10 \%$ 
Table 3. Physical data and yields of 1-N-higher-acyl-3,6'-bis( $N$-benzyloxycarbonyl)kanamycin A derivatives (5).

\begin{tabular}{|c|c|c|c|c|}
\hline No. & $\mathrm{R}$ & $\begin{array}{c}\text { Yield } \\
(\%)\end{array}$ & IR (Nujol, $\mathrm{cm}^{-1}$ ) & NMR $\left(\mathrm{DMSO}-d_{\hat{\delta}}, \delta\right)$ \\
\hline $5 a$ & $\mathrm{CO}\left(\mathrm{CH}_{2}\right)_{13} \mathrm{CH}_{3}$ & 92 & $\begin{array}{l}1710,1685,1640,1530 \\
1265\end{array}$ & $0.86\left(3 \mathrm{H}, \mathrm{m}, \mathrm{CH}_{3}\right)$ \\
\hline $5 b$ & $\mathrm{CO}\left(\mathrm{CH}_{2}\right)_{14} \mathrm{CH}_{3}$ & 85 & $\begin{array}{l}1680,1640,1540,1275 \\
1230\end{array}$ & $\begin{array}{l}0.90\left(3 \mathrm{H}, \mathrm{m}, \mathrm{CH}_{3}\right), \\
1.62\left(26 \mathrm{H}, \mathrm{s}, \mathrm{CH}_{2}\right)\end{array}$ \\
\hline $5 c$ & 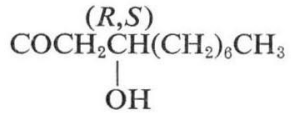 & 86 & $1690,1640,1540,1150$ & $0.92\left(3 \mathrm{H}, \mathrm{m}, \mathrm{CH}_{3}\right)$ \\
\hline $5 d$ & $\begin{array}{c}(R, S) \\
\mathrm{COCH}_{2} \mathrm{CH}\left(\mathrm{CH}_{2}\right)_{10} \mathrm{CH}_{3} \\
\text { OH }\end{array}$ & 93 & $1690,1640,1540,1150$ & $0.95\left(3 \mathrm{H}, \mathrm{m}, \mathrm{CH}_{3}\right)$ \\
\hline $5 e$ & 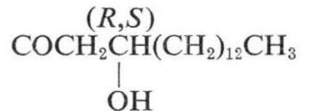 & 93 & $\begin{array}{l}1690,1640,1540,1270 \\
1230\end{array}$ & $0.90\left(3 \mathrm{H}, \mathrm{m}, \mathrm{CH}_{3}\right)$ \\
\hline $5 f$ & 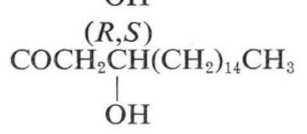 & 54 & $1680,1640,1540,1150$ & $0.90\left(3 \mathrm{H}, \mathrm{m}, \mathrm{CH}_{3}\right)$ \\
\hline
\end{tabular}

palladium on carbon, followed by lyophilization, gave the corresponding $1-N$-acyl-3"- $N$-functionalized acylkanamycin A derivatives (7c, $\mathbf{k}, \mathbf{0}, \mathbf{8 c}, \mathbf{9 b}, \mathbf{c})$ as summarized in Tables 7, 8 and 9.

\section{Biological Activity}

Effect of Acyl Group at the $N-3^{\prime \prime}$ Position of 1- $N$-Palmitoylkanamycin A

Antiviral activity against HSV-I and influenza virus and cytotoxicity of the 3 "- $N$-acylkanamycin A derivatives (7) having palmitoyl group at the $N-1$ position are summarized in Table 10.

Antiviral Activity against HSV-I:

The $3^{\prime \prime}-N$-unsubstituted (7a), $3^{\prime \prime}-N$-formyl (7b), $3^{\prime \prime}-N$-acetyl analogs (7c) having palmitoyl group at the $N$-1 position exhibited excellent antiviral activity against HSV-I $\left(\right.$ ID $\left._{50} 1.0 \sim 3.2 \mu \mathrm{g} / \mathrm{ml}\right)$ and were about 30 times more active than virazole ${ }^{4)}$, though they were 20 times less active than acyclovir ${ }^{5)}$. The 1- $N$-palmitoyl analogs $(7 \mathrm{~d}, \mathbf{e}, \mathbf{f})$ having propionyl, butyryl, or iso-butyryl group at the $\mathrm{N}$-3" position also showed remarkable antiviral activity against HSV-I $\left(\mathrm{ID}_{50} 1.7 \sim 4.8 \mu \mathrm{g} / \mathrm{ml}\right)$. Further, the analogs $(7 \mathrm{~g}, \mathrm{~h}, \mathbf{i})$ having a bulky acyl group, such as tert-butylacetyl, benzoyl, or adamantylacetyl group, exhibited remarkable activity against HSV-I ( ID $\left._{50} 2.7 \sim 3.2 \mu \mathrm{g} / \mathrm{ml}\right)$. The $3^{\prime \prime}-N$-chloroacetyl analog (7j) showed similar activity against HSV-I to the $3^{\prime \prime}-N$-trifluoroacetyl analog (7u). However, the analogs $(7 \mathrm{k}, 1, \mathrm{~m})$ having an acyl group with hydroxyl radical, such as hydroxyacetyl, 2-hydroxypropionyl, or 3-hydroxybutyryl group were about 2 times less active $\left(\mathrm{ID}_{50} 2.7 \sim 7.8 \mu \mathrm{g} / \mathrm{ml}\right)$ than $7 \mathrm{u}$. The $3^{\prime \prime}-N$-glycyl analog (7o) exhibited the strongest antiviral activity against HSV-I (ID $\left.501.0 \mu \mathrm{g} / \mathrm{ml}\right)$ in this series and was 30 times more active than virazole, but was 30 times less active than acyclovir. Furthermore, the $3^{\prime \prime}-N$-carbamoyl (7n), 3"- $N$-((S)-3-amino-2-hydroxypropionyl) (7p), and $3^{\prime \prime}-N-(S)-(2,4-$ diaminobutyryl) (7q) analogs were about 3 times less active than $7 \mathbf{u}$.

The cytotoxicity of these $3^{\prime \prime}-N$-acyl derivatives (7) tended to increase as compared with that of $3^{\prime \prime}-N$-trifluoroacetyl derivative (7u). 
Table 4. Physical data and yields of 1-N-palmitoyl-3,6'-bis( $N$-benzyloxycarbonyl)- $3^{\prime \prime}-N$-acylkanamycin A derivatives $(6 \mathrm{~A} \sim \mathrm{T})$.

$\mathrm{R}=\mathrm{CO}\left(\mathrm{CH}_{2}\right)_{14} \mathrm{CH}_{3}$

\begin{tabular}{|c|c|c|c|c|c|c|}
\hline No. & $\mathrm{R}^{\prime}$ & Method & $\begin{array}{l}\text { Yield } \\
(\%)\end{array}$ & $\begin{array}{c}\mathrm{MP} \\
\left({ }^{\circ} \mathrm{C}, \mathrm{dec}\right)\end{array}$ & IR (Nujol, $\mathrm{cm}^{-1}$ ) & $\operatorname{NMR}\left(\mathrm{DMSO}-d_{\theta}, \delta\right)$ \\
\hline $\begin{array}{r}6 \mathrm{~A} \\
(5 \mathrm{~b})\end{array}$ & $\mathrm{H}$ & - & 85 & $-^{\mathrm{a}}$ & $\begin{array}{l}1680,1640,1540, \\
1275,1230\end{array}$ & $\begin{array}{l}0.90\left(3 \mathrm{H}, \mathrm{m}, \mathrm{CH}_{3}\right), \\
1.62\left(26 \mathrm{H}, \mathrm{s}, \mathrm{CH}_{2}\right)\end{array}$ \\
\hline $6 \mathrm{~B}$ & $\mathrm{CHO}$ & - & 85 & 261 & $\begin{array}{l}1690,1640,1530 \\
1280,1230\end{array}$ & $\begin{array}{l}0.90\left(3 \mathrm{H}, \mathrm{m}, \mathrm{CH}_{3}\right) \\
8.10(1 \mathrm{H}, \mathrm{s}, \mathrm{CHO})\end{array}$ \\
\hline $6 \mathrm{C}$ & $\mathrm{COCH}_{3}$ & - & 98 & - & $\begin{array}{l}1680,1640,1520, \\
1270,1230\end{array}$ & $\begin{array}{l}0.85\left(3 \mathrm{H}, \mathrm{m}, \mathrm{CH}_{3}\right), \\
1.83\left(3 \mathrm{H}, \mathrm{s}, \mathrm{CH}_{3} \mathrm{CO}\right)\end{array}$ \\
\hline $6 \mathrm{D}$ & $\mathrm{COCH}_{2} \mathrm{CH}_{3}$ & $\mathrm{~A}$ & 84 & - & $\begin{array}{l}1710,1690,1640, \\
1545,1270\end{array}$ & $\begin{array}{l}0.70 \sim 1.10 \\
\left(6 \mathrm{H}, \mathrm{m}, \mathrm{CH}_{3} \mathrm{CH}_{2}\right)\end{array}$ \\
\hline $6 \mathrm{E}$ & $\mathrm{COCH}=\mathrm{CHCH}_{3}$ & A & 100 & 228 & $\begin{array}{l}1685,1620,1530, \\
1260\end{array}$ & $0.90\left(3 \mathrm{H}, \mathrm{m}, \mathrm{CH}_{3}\right)$ \\
\hline $6 \mathrm{~F}$ & $\mathrm{COCH}\left(\mathrm{CH}_{3}\right)_{2}$ & A & 99 & 255 & $\begin{array}{l}1690,1630,1530, \\
1270\end{array}$ & \\
\hline $6 \mathrm{G}$ & $\mathrm{COCH}_{2} \mathrm{C}\left(\mathrm{CH}_{3}\right)_{3}$ & B & 91 & 256 & $\begin{array}{l}1720,1680,1620, \\
1540\end{array}$ & \\
\hline $6 \mathrm{H}$ & $\mathrm{COC}_{6} \mathrm{H}_{5}$ & A & 88 & 284 & $\begin{array}{l}1710,1680,1620, \\
1540,1300\end{array}$ & $\begin{array}{l}0.90\left(3 \mathrm{H}, \mathrm{m}, \mathrm{CH}_{3}\right), \\
1.20\left(26 \mathrm{H}, \mathrm{s}, \mathrm{CH}_{2}\right)\end{array}$ \\
\hline $6 I$ & & C & 100 & 254 & $\begin{array}{l}1680,1615,1530, \\
1260\end{array}$ & \\
\hline $6 \mathrm{~J}$ & $\mathrm{COCH}_{2} \mathrm{Cl}$ & A & 100 & 238 & $\begin{array}{l}1690,1640,1540, \\
1270\end{array}$ & $\begin{array}{l}0.90\left(3 \mathrm{H}, \mathrm{m}, \mathrm{CH}_{3}\right) \\
1.20\left(26 \mathrm{H}, \mathrm{s}, \mathrm{CH}_{2}\right)\end{array}$ \\
\hline $6 \mathrm{~K}$ & $\mathrm{COCH}_{2} \mathrm{OCH}_{2} \mathrm{C}_{6} \mathrm{H}_{5}$ & - & 99 & $-^{a}$ & $1690,1640,1540$ & $\begin{array}{l}1.20\left(26 \mathrm{H}, \mathrm{s}, \mathrm{CH}_{2}\right), \\
4.57\left(2 \mathrm{H}, \mathrm{s}, \mathrm{CH}_{2}\right), \\
7.25(5 \mathrm{H}, \mathrm{s}), 7.30 \\
(5 \mathrm{H}, \mathrm{s}), 7.33(5 \mathrm{H}, \mathrm{s})\end{array}$ \\
\hline $6 \mathrm{~L}$ & $\begin{array}{c}\mathrm{COCHCH}_{3} \\
\text { OH } \\
(R, S)\end{array}$ & $\mathrm{C}$ & 94 & 232 & $\begin{array}{l}1720,1680,1640 \\
1530,1280\end{array}$ & $0.90\left(3 \mathrm{H}, \mathrm{m}, \mathrm{CH}_{3}\right)$ \\
\hline $6 \mathrm{M}$ & $\begin{array}{c}\mathrm{COCH}_{2} \mathrm{CHCH} \\
\left.\right|_{\mathrm{OH}}\end{array}$ & $\mathrm{C}$ & 91 & 205 & $\begin{array}{l}1720,1690,1640 \\
1540,1270\end{array}$ & $0.90\left(3 \mathrm{H}, \mathrm{m}, \mathrm{CH}_{3}\right)$ \\
\hline $6 \mathrm{~N}$ & CONHZ & $\mathrm{D}$ & 100 & - & $\begin{array}{l}1785,1685,1530, \\
1300,1250\end{array}$ & $0.90\left(3 \mathrm{H}, \mathrm{m}, \mathrm{CH}_{3}\right)$ \\
\hline 60 & $\mathrm{COCH}_{2} \mathrm{NHZ}$ & - & 87 & 269 & $\begin{array}{l}1690,1650,1540, \\
1270\end{array}$ & $\begin{array}{l}0.90\left(3 \mathrm{H}, \mathrm{m}, \mathrm{CH}_{3}\right), \\
1.22\left(26 \mathrm{H}, \mathrm{s}, \mathrm{CH}_{2}\right)\end{array}$ \\
\hline $6 \mathrm{P}$ & $\begin{array}{c}\mathrm{COCHCH}_{2} \mathrm{NHZ} \\
\quad \mid \\
\mathrm{OH} \\
(S)\end{array}$ & $\mathrm{C}$ & 20 & 255 & $\begin{array}{l}1680,1630,1520 \\
1260\end{array}$ & $\begin{array}{l}0.90\left(3 \mathrm{H}, \mathrm{m}, \mathrm{CH}_{3}\right), \\
1.25\left(26 \mathrm{H}, \mathrm{s}, \mathrm{CH}_{2}\right)\end{array}$ \\
\hline $6 \mathrm{Q}$ & $\begin{array}{c}\mathrm{COCHCH}_{2} \mathrm{CH}_{2} \mathrm{NHZ} \\
\mathrm{NHZ}\end{array}$ & $\mathrm{C}$ & 69 & 230 & $\begin{array}{l}1690,1640,1300, \\
1225\end{array}$ & $0.90\left(3 \mathrm{H}, \mathrm{m}, \mathrm{CH}_{3}\right)$ \\
\hline $6 \mathbf{R}$ & $\mathrm{COCH}_{2} \mathrm{CH}_{2} \mathrm{COOH}$ & - & 99 & 252 & $\begin{array}{l}1690,1640,1530, \\
1270\end{array}$ & \\
\hline $6 \mathrm{~S}$ & $\mathrm{COC}_{6} \mathrm{H}_{4} \mathrm{COOH}(o)$ & - & 20 & 263 & $1700,1640,1530$ & $0.90\left(3 \mathrm{H}, \mathrm{m}, \mathrm{CH}_{3}\right)$ \\
\hline $6 \mathrm{~T}$ & $\mathrm{COCH}_{2} \mathrm{NHCHO}$ & C & 58 & 253 & $\begin{array}{l}1690,1640,1540, \\
1280,1230\end{array}$ & $\begin{array}{l}0.90\left(3 \mathrm{H}, \mathrm{m}, \mathrm{CH}_{3}\right), \\
1.23\left(26 \mathrm{H}, \mathrm{s}, \mathrm{CH}_{2}\right)\end{array}$ \\
\hline
\end{tabular}

a Not measured. 
Table 5. Physical data and yields of 3,6'-bis( $N$-benzyloxycarbonyl)-1- $N$-(3-hydroxytetradecanoyl)- $3^{\prime \prime}-N$ acylkanamycin A derivatives $(6 \mathbf{U} \sim \mathbb{Z})$.

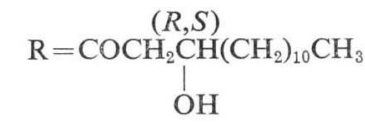

\begin{tabular}{|c|c|c|c|c|c|c|}
\hline No. & $\mathrm{R}^{\prime}$ & Method & $\begin{array}{l}\text { Yield } \\
(\%)\end{array}$ & $\begin{array}{c}\mathrm{MP} \\
\left({ }^{\circ} \mathrm{C}, \mathrm{dec}\right)\end{array}$ & IR (Nujol, $\mathrm{cm}^{-1}$ ) & NMR (DMSO- $\left.d_{6}, \delta\right)$ \\
\hline $\begin{array}{r}6 \mathrm{U} \\
(5 \mathrm{~d})\end{array}$ & $\mathrm{H}$ & - & 93 & $-^{\mathrm{a}}$ & $\begin{array}{l}1690,1640,1540, \\
1150\end{array}$ & $0.95\left(3 \mathrm{H}, \mathrm{m}, \mathrm{CH}_{3}\right)$ \\
\hline $6 \mathrm{~V}$ & $\mathrm{CHO}$ & 一 & 91 & 251 & $\begin{array}{l}1690,1645,1535, \\
1280\end{array}$ & $0.90\left(3 \mathrm{H}, \mathrm{m}, \mathrm{CH}_{3}\right)$ \\
\hline $6 W$ & $\mathrm{COCH}_{3}$ & - & 80 & 266 & $\begin{array}{l}1685,1640,1520, \\
1270\end{array}$ & $1.84\left(3 \mathrm{H}, \mathrm{s}, \mathrm{CH}_{3} \mathrm{CO}\right)$ \\
\hline $6 \mathrm{X}$ & $\mathrm{COCF}_{3}$ & - & 89 & 265 & $\begin{array}{l}1690,1640,1540, \\
1270\end{array}$ & $\begin{array}{l}0.88\left(3 \mathrm{H}, \mathrm{m}, \mathrm{CH}_{3}\right), \\
1.22\left(20 \mathrm{H}, \mathrm{s}, \mathrm{CH}_{2}\right)\end{array}$ \\
\hline $6 \mathrm{Y}$ & $\begin{array}{l}\mathrm{COCH}_{2} \mathrm{NHZ} \\
(S)\end{array}$ & B & 99 & 218 & $1680,1520,1260$ & $0.90\left(3 \mathrm{H}, \mathrm{m}, \mathrm{CH}_{3}\right)$ \\
\hline $6 \mathrm{Z}$ & $\begin{array}{c}\mathrm{COCHCH}_{2} \mathrm{NHZ} \\
\mathrm{OH}\end{array}$ & $\mathrm{C}$ & 77 & 238 & $\begin{array}{l}1690,1640,1530, \\
1265\end{array}$ & $\begin{array}{l}0.92\left(3 \mathrm{H}, \mathrm{m}, \mathrm{CH}_{3}\right), \\
1.25\left(20 \mathrm{H}, \mathrm{s}, \mathrm{CH}_{2}\right)\end{array}$ \\
\hline
\end{tabular}

a Not measured.

Table 6. Physical data and yields of 1- $N$-higher-acyl-3,6'-bis( $N$-benzyloxycarbonyl)- $3^{\prime \prime}-N-[(N$-benzyloxycarbonyl)glycyl]kanamycin A derivatives (6a $\sim \mathbf{f})$.

$\mathrm{R}^{\prime}=\mathrm{COCH}_{2} \mathrm{NHZ}$

\begin{tabular}{|c|c|c|c|c|c|c|}
\hline No. & $\mathrm{R}$ & Method & $\begin{array}{l}\text { Yield } \\
(\%)\end{array}$ & $\begin{array}{c}\mathrm{MP} \\
\left({ }^{\circ} \mathrm{C}, \mathrm{dec}\right)\end{array}$ & IR (Nujol, $\mathrm{cm}^{-1}$ ) & NMR (DMSO- $\left.d_{6}, \delta\right)$ \\
\hline $6 a$ & $\mathrm{CO}\left(\mathrm{CH}_{2}\right)_{13} \mathrm{CH}_{3}$ & B & 85 & 217 & $1690,1535,1270$ & $0.92\left(3 \mathrm{H}, \mathrm{m}, \mathrm{CH}_{3}\right)$ \\
\hline $6 b$ & $\mathrm{COO}\left(\mathrm{CH}_{2}\right)_{15} \mathrm{CH}_{3}$ & - & 57 & 246 & $1690,1540,1270$ & $0.90\left(3 \mathrm{H}, \mathrm{m}, \mathrm{CH}_{3}\right)$ \\
\hline $6 c$ & $\begin{array}{c}\mathrm{CONH}\left(\mathrm{CH}_{2}\right)_{14} \mathrm{CH}_{3} \\
(R, S)\end{array}$ & - & 56 & 251 & $1690,1540,1270$ & $0.91\left(3 \mathrm{H}, \mathrm{m}, \mathrm{CH}_{3}\right)$ \\
\hline $6 d$ & $\begin{array}{c}\mathrm{COCH}_{2} \mathrm{CH}\left(\mathrm{CH}_{2}\right)_{8} \mathrm{CH}_{3} \\
{ }_{\mathrm{OH}}\end{array}$ & B & 91 & $-^{\mathrm{a}}$ & $\begin{array}{l}1695,1640,1540 \\
1270\end{array}$ & $0.91\left(3 \mathrm{H}, \mathrm{m}, \mathrm{CH}_{3}\right)$ \\
\hline $6 e$ & $\underset{\mathrm{COCH}_{2} \mathrm{CH}\left(\mathrm{CH}_{2}\right)_{12} \mathrm{CH}_{3}}{(R, S)}$ & B & 100 & - & $\begin{array}{l}1690,1640,1540 \\
1270\end{array}$ & $0.91\left(3 \mathrm{H}, \mathrm{m}, \mathrm{CH}_{3}\right)$ \\
\hline $6 f$ & $\underset{\mathrm{OOCH}_{2} \mathrm{CH}\left(\mathrm{CH}_{2}\right)_{14} \mathrm{CH}_{3}}{\mathrm{CH}_{3}}$ & B & 99 & - & $1690,1640,1540$ & $0.90\left(3 \mathrm{H}, \mathrm{m}, \mathrm{CH}_{3}\right)$ \\
\hline
\end{tabular}

a Not measured.

Antiviral Activity against Influenza Virus:

Antiviral activity of the 1-N-palmitoyl-3"'-N-acylkanamycin A derivatives (7) against influenza virus tended to be similar to antiviral activity against HSV-I. The 1- $N$-palmitoyl analogs (7a $\sim \mathbf{d})$ exhibited remarkable antiviral activity against influenza virus $\left(\mathrm{ID}_{50} 10 \sim 32 \mu \mathrm{g} / \mathrm{ml}\right)$ and showed similar activity to $7 \mathbf{u}$. However, analogs (7f, $\mathbf{h}, \mathbf{i})$ having a bulky acyl group at the $N-3^{\prime \prime}$ position tended to decrease antiviral activity against influenza virus. Further, analogs $(7 \mathbf{k} \sim \mathbf{q})$ having an acyl group with functional groups (hydroxyl and/or amino group(s)) at the $N-3^{\prime \prime}$ position exhibited much less antiviral activity against influenza virus, and their activity was about 6 times less than that of amantadine ${ }^{6}$. 
Table 7. Physical data and yields of 1-N-palmitoyl-3"'-N-acylkanamycin A derivatives (7).

$\mathrm{R}=\mathrm{CO}\left(\mathrm{CH}_{2}\right)_{14} \mathrm{CH}_{3}$

\begin{tabular}{|c|c|c|c|c|c|c|c|c|}
\hline \multirow{2}{*}{ No. } & \multirow{2}{*}{$\mathrm{R}^{\prime}$} & \multirow{2}{*}{$\begin{array}{l}\text { Yield } \\
(\%)\end{array}$} & \multirow{2}{*}{$\begin{array}{c}\text { MP } \\
\left({ }^{\circ} \mathrm{C}, \mathrm{dec}\right)\end{array}$} & \multirow{2}{*}{$\begin{array}{c}{[\alpha]_{\mathrm{H}}^{20}\left({ }^{\circ}\right)} \\
\left(\mathrm{H}_{2} \mathrm{O}\right)\end{array}$} & \multirow{2}{*}{ IR (Nujol, $\mathrm{cm}^{-1}$ ) } & \multicolumn{2}{|r|}{ NMR } & \multirow{2}{*}{$\underset{(m / z)}{\text { FD-MS }}$} \\
\hline & & & & & & Solvent & $\delta(\mathrm{ppm})$ & \\
\hline $7 a$ & $\mathrm{H}$ & 87 & 221 & $\begin{array}{l}+71.1 \\
(c 0.5)\end{array}$ & $\begin{array}{l}1640 \sim 1630,1540, \\
1510^{\mathrm{b}}\end{array}$ & $\mathrm{D}_{2} \mathrm{O}$ & $\begin{array}{l}0.91\left(3 \mathrm{H}, \mathrm{m}, \mathrm{CH}_{3}\right), 1.26(26 \mathrm{H}, \\
\left.\mathrm{s}, \mathrm{CH}_{2}\right)\end{array}$ & $723\left(\mathrm{M}^{+}\right)$ \\
\hline $7 \mathrm{c}$ & $\mathrm{COCH}_{3}$ & 100 & 193 & $\begin{array}{r}+74.5 \\
(c 1.0)\end{array}$ & 1630,1540 & $\mathrm{D}_{2} \mathrm{O}$ & $\begin{array}{l}0.83\left(3 \mathrm{H}, \mathrm{m}, \mathrm{CH}_{3}\right), 1.23(26 \mathrm{H} \\
\left.\mathrm{s}, \mathrm{CH}_{2}\right), 2.02\left(3 \mathrm{H}, \mathrm{s}, \mathrm{CH}_{3} \mathrm{CO}\right)\end{array}$ & $765\left(\mathrm{M}^{+}\right)$ \\
\hline $7 e$ & $\mathrm{COCH}_{2} \mathrm{CH}_{2} \mathrm{CH}_{3}$ & 69 & 158 & $\begin{array}{l}+71.5 \\
(c 0.5)\end{array}$ & 1630,1540 & $\mathrm{D}_{2} \mathrm{O}$ & $0.96\left(6 \mathrm{H}, \mathrm{m}, \mathrm{CH}_{3}\right)$ & $793\left(\mathrm{M}^{+}\right)$ \\
\hline $7 \mathrm{f}$ & $\mathrm{COCH}\left(\mathrm{CH}_{3}\right)_{2}$ & 64 & 144 & $\begin{array}{l}+45.9 \\
(c 1.0)\end{array}$ & 1640,1550 & $\mathrm{CD}_{3} \mathrm{OD}$ & $5.08(1 \mathrm{H}, \mathrm{d}, J=4 \mathrm{~Hz})$ & $793\left(\mathrm{M}^{+}\right)$ \\
\hline $7 \mathrm{~g}$ & $\mathrm{COCH}_{2} \mathrm{C}\left(\mathrm{CH}_{3}\right)_{3}$ & 76 & 137 & $\begin{array}{l}+45.3 \\
(c 1.0)\end{array}$ & 1630,1540 & $\mathrm{CD}_{3} \mathrm{OD}$ & $\begin{array}{l}1.05\left(9 \mathrm{H}, \mathrm{s}, \mathrm{CH}_{3}\right), 5.50(1 \mathrm{H}, \mathrm{d}, \\
J=3 \mathrm{~Hz})\end{array}$ & $821\left(\mathrm{M}^{+}\right)$ \\
\hline
\end{tabular}




\begin{tabular}{|c|c|c|c|c|c|c|c|c|}
\hline $7 \mathrm{k}$ & $\mathrm{COCH}_{2} \mathrm{OH}$ & 91 & 159 & $\begin{array}{l}+73.2 \\
(c 0.55)\end{array}$ & 1640,1550 & $\mathrm{CD}_{3} \mathrm{OD}$ & $5.10(1 \mathrm{H}, \mathrm{d}, J=3 \mathrm{~Hz}), 5.47(1 \mathrm{H})$ & $803\left(\mathrm{M}^{+}+\mathrm{Na}\right)$ \\
\hline 71 & $\begin{array}{l}(R, S) \\
\mathrm{COCHCH}_{3} \\
\quad \mathrm{OH}^{-}\end{array}$ & 99 & 122 & $-^{a}$ & $1700,1630,1220^{\mathrm{b}}$ & $\mathrm{CD}_{3} \mathrm{OD}$ & $0.90\left(3 \mathrm{H}, \mathrm{m}, \mathrm{CH}_{3}\right)$ & \\
\hline $7 \mathrm{~m}$ & $\begin{array}{c}(R, S) \\
\mathrm{COCH}_{2} \mathrm{CHCH} \\
! \\
\mathrm{OH}\end{array}$ & 76 & 121 & - & $1720,1630,1240$ & $\mathrm{CD}_{3} \mathrm{OD}$ & $0.90\left(3 \mathrm{H}, \mathrm{m}, \mathrm{CH}_{3}\right)$ & $810\left(\mathrm{M}^{+}+1\right)$ \\
\hline $7 \mathrm{n}$ & $\mathrm{CONH}_{2}$ & 70 & 194 & $\begin{array}{l}+62.1 \\
(c 1.0)\end{array}$ & $1700,1630,1540,1240$ & $\mathrm{CD}_{3} \mathrm{OD}$ & $\begin{array}{l}0.95\left(3 \mathrm{H}, \mathrm{m}, \mathrm{CH}_{3}\right), 5.10(1 \mathrm{H}, \mathrm{d} \\
J=3 \mathrm{~Hz}), 5.51(1 \mathrm{H}, \mathrm{d}, J=3 \mathrm{~Hz})\end{array}$ & \\
\hline 70 & $\mathrm{COCH}_{2} \mathrm{NH}_{2}$ & 79 & 163 & $\begin{array}{l}+47.6 \\
(c 1.0)\end{array}$ & $1620,1560,1300,1140$ & $\mathrm{CD}_{3} \mathrm{OD}$ & $\underset{\left.\mathrm{CH}_{2}\right)}{0.97}\left(3 \mathrm{H}, \mathrm{m}, \mathrm{CH}_{3}\right), 1.30(26 \mathrm{H}, \mathrm{s}$ & $780\left(\mathrm{M}^{+}\right)$ \\
\hline $7 p$ & $\begin{array}{l}\stackrel{(S)}{S} \underset{\mathrm{COCHCH}}{ } \mathrm{NH}_{2} \\
\quad \mathrm{OH}_{\mathrm{O}}\end{array}$ & 58 & 168 & $\begin{array}{l}+39.7 \\
(c 0.5)\end{array}$ & $1640,1540,1140^{\mathrm{b}}$ & $\mathrm{CD}_{3} \mathrm{OD}$ & $\begin{array}{l}0.95\left(3 \mathrm{H}, \mathrm{m}, \mathrm{CH}_{3}\right), 5.08(1 \mathrm{H}, \mathrm{d} \\
J=3.5 \mathrm{~Hz})\end{array}$ & $810\left(\mathrm{M}^{+}\right)$ \\
\hline $7 q$ & $\begin{array}{l}\stackrel{(S)}{\mathrm{COCHCH}} \mathrm{CH}_{2} \mathrm{CH}_{2} \mathrm{NH}_{2} \\
\underset{\mathrm{NH}_{2}}{\mathrm{C}}\end{array}$ & 12 & 125 & - & $1710,1640,1540,1215$ & $\mathrm{CD}_{3} \mathrm{OD}$ & $0.92\left(3 \mathrm{H}, \mathrm{m}, \mathrm{CH}_{3}\right)$ & - \\
\hline $7 \mathrm{r}$ & $\mathrm{COCH}_{2} \mathrm{CH}_{2} \mathrm{COOH}$ & 96 & 145 & $\begin{array}{l}+54.0 \\
(c 1.0)\end{array}$ & $1720,1640,1550,1140$ & $\mathrm{CD}_{3} \mathrm{OD}$ & $\begin{array}{l}2.60(4 \mathrm{H}, \mathrm{s}), 5.50(1 \mathrm{H}, \mathrm{d} \\
J=3 \mathrm{~Hz})\end{array}$ & - \\
\hline $7 \mathrm{~s}$ & $\mathrm{COC}_{6} \mathrm{H}_{4} \mathrm{COOH}(o)$ & 64 & 213 & - & $1770,1710,1635,1510$ & $\mathrm{CD}_{3} \mathrm{OD}$ & $0.93\left(3 \mathrm{H}, \mathrm{m}, \mathrm{CH}_{3}\right)$ & - \\
\hline $7 \mathrm{t}$ & $\mathrm{COCH}_{2} \mathrm{NHCHO}$ & 55 & 138 & $\begin{array}{l}+60.2 \\
(c 1.0)\end{array}$ & $1665,1560,1290$ & $\mathrm{CD}_{3} \mathrm{OD}$ & $\begin{array}{l}0.93\left(3 \mathrm{H}, \mathrm{m}, \mathrm{CH}_{3}\right), 5.10(1 \mathrm{H}, \mathrm{d}, \\
J=3 \mathrm{~Hz})\end{array}$ & - \\
\hline
\end{tabular}

${ }^{a}$ Not measured, ${ }^{\text {b }} \mathrm{KBr}$ disk method. 
Table 8. Physical data and yields of 1-N-(3-hydroxytetradecanoyl)-3"- $N$-acylkanamycin A derivatives (8). $(R, S)$

$\mathrm{R}=\mathrm{COCH}_{2} \mathrm{CH}\left(\mathrm{CH}_{2}\right)_{10} \mathrm{CH}_{3}$

$\mathrm{OH}$

\begin{tabular}{|c|c|c|c|c|c|c|c|c|}
\hline \multirow{2}{*}{ No. } & \multirow{2}{*}{$\mathrm{R}^{\prime}$} & \multirow{2}{*}{$\begin{array}{l}\text { Yield } \\
(\%)\end{array}$} & \multirow{2}{*}{$\begin{array}{c}\mathrm{MP} \\
\left({ }^{\circ} \mathrm{C}, \mathrm{dec}\right)\end{array}$} & \multirow{2}{*}{$\begin{array}{l}{[\alpha]_{\mathrm{D}}^{20}\left({ }^{\circ}\right)} \\
\left(\mathrm{H}_{2} \mathrm{O}\right)\end{array}$} & \multirow{2}{*}{ IR (Nujol, $\mathrm{cm}^{-1}$ ) } & \multicolumn{2}{|r|}{ NMR } & \multirow{2}{*}{$\begin{array}{c}\text { FD-MS } \\
(\mathrm{m} / \mathrm{z})\end{array}$} \\
\hline & & & & & & Solvent & $\delta(\mathrm{ppm})$ & \\
\hline $8 a$ & $\mathrm{H}$ & 82 & 178 & $\begin{array}{l}+80.8 \\
(c 0.5)\end{array}$ & 1630,1140 & $-^{a}$ & - & $711\left(\mathrm{M}^{+}\right)$ \\
\hline $8 b$ & $\mathrm{CHO}$ & 62 & 164 & $\begin{array}{l}+87.6 \\
(c 1.0)\end{array}$ & $1650 \sim 1550,1140$ & $\mathrm{CD}_{3} \mathrm{OD}$ & $\begin{array}{l}0.93\left(3 \mathrm{H}, \mathrm{m}, \mathrm{CH}_{3}\right), 8.23(1 \mathrm{H}, \mathrm{s}, \\
\text { CHO) }\end{array}$ & - \\
\hline $8 \mathrm{c}$ & $\mathrm{COCH}_{3}$ & 88 & 113 & $\begin{array}{l}+71.8 \\
(c 1.0)\end{array}$ & $1630,1560,1140$ & $\mathrm{CD}_{3} \mathrm{OD}$ & $\begin{array}{l}2.10\left(3 \mathrm{H}, \mathrm{s}, \mathrm{CH}_{3} \mathrm{CO}\right), 5.45(1 \mathrm{H} \\
\text { d, } J=4 \mathrm{~Hz})\end{array}$ & - \\
\hline $8 d$ & $\mathrm{COCF}_{3}$ & 85 & 116 & $\begin{array}{l}+63.8 \\
(c 1.0)\end{array}$ & $1700,1630,1560,1150$ & $\mathrm{CD}_{3} \mathrm{OD}$ & $\begin{array}{l}5.13(1 \mathrm{H}, \mathrm{d}, J=3 \mathrm{~Hz}), 5.23(1 \mathrm{H}, \\
\mathrm{d}, J=3 \mathrm{~Hz})\end{array}$ & $807\left(\mathrm{M}^{+}\right)$ \\
\hline $8 \mathrm{e}$ & $\mathrm{COCH}_{2} \mathrm{NH}_{2}$ & 52 & 146 & $\begin{array}{l}+58.6 \\
(\text { c } 1.0)\end{array}$ & $1630,1560,1025^{\mathrm{b}}$ & $\mathrm{CD}_{3} \mathrm{OD}$ & $0.94\left(3 \mathrm{H}, \mathrm{m}, \mathrm{CH}_{3}\right)$ & $768\left(\mathrm{M}^{+}\right)$ \\
\hline $8 \mathrm{f}$ & 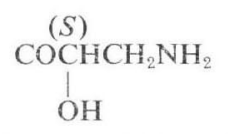 & 64 & 125 & $\begin{array}{l}+40.7 \\
(c 1.0)\end{array}$ & $1750,1640,1140$ & $\mathrm{CD}_{3} \mathrm{OD}$ & $\begin{array}{l}0.93\left(3 \mathrm{H}, \mathrm{m}, \mathrm{CH}_{3}\right) \\
5.13(1 \mathrm{H}, \mathrm{d}, J=3 \mathrm{~Hz})\end{array}$ & $\begin{array}{l}797 \\
\left(\mathrm{M}^{+}-1\right)\end{array}$ \\
\hline
\end{tabular}

a Not measured, b $\mathrm{KBr}$ disk method. 
Table 9. Physical data and yields of 1-N-higher-acyl-3" $-N$-glycylkanamycin A derivatives (9).

$\mathrm{R}^{\prime}=\mathrm{COCH}_{2} \mathrm{NH}_{2}$

\begin{tabular}{|c|c|c|c|c|c|c|c|c|}
\hline \multirow{2}{*}{ No. } & \multirow{2}{*}{$\mathrm{R}$} & \multirow{2}{*}{$\begin{array}{l}\text { Yield } \\
(\%)\end{array}$} & \multirow{2}{*}{$\begin{array}{c}\mathrm{MP} \\
\left({ }^{\circ} \mathrm{C}, \mathrm{dec}\right)\end{array}$} & \multirow{2}{*}{$\begin{array}{c}[\alpha]]_{\mathrm{D}}^{20}\left({ }^{\circ}\right) \\
\left(\mathrm{H}_{2} \mathrm{O}\right)\end{array}$} & \multirow{2}{*}{ IR (Nujol, $\mathrm{cm}^{-1}$ ) } & \multicolumn{2}{|r|}{ NMR } & \multirow{2}{*}{$\begin{array}{c}\text { FD-MS } \\
(m / z)\end{array}$} \\
\hline & & & & & & Solvent & $\delta(\mathrm{ppm})$ & \\
\hline $9 \mathrm{a}$ & $\mathrm{CO}\left(\mathrm{CH}_{2}\right)_{13} \mathrm{CH}_{3}$ & 100 & 97 & $-^{a}$ & 1670,1300 & $\mathrm{CD}_{3} \mathrm{OD}$ & $\begin{array}{l}0.93\left(3 \mathrm{H}, \mathrm{m}, \mathrm{CH}_{3}\right), \\
5.23(1 \mathrm{H}, \mathrm{d}, J=4 \mathrm{~Hz}), \\
5.55(1 \mathrm{H}, \mathrm{d}, J=3 \mathrm{~Hz})\end{array}$ & $\begin{array}{l}788\left(\mathrm{M}^{+}+\mathrm{Na}\right) \\
766\left(\mathrm{M}^{+}+1\right)\end{array}$ \\
\hline $9 \mathrm{~b}$ & $\mathrm{COO}\left(\mathrm{CH}_{2}\right)_{15} \mathrm{CH}_{3}$ & 60 & 197 & $\begin{array}{l}+58.4 \\
(c 1.0)\end{array}$ & $1690,1540,1260$ & $\mathrm{CD}_{3} \mathrm{OD}$ & $0.95\left(3 \mathrm{H}, \mathrm{m}, \mathrm{CH}_{3}\right)$ & - \\
\hline $9 \mathrm{c}$ & $\mathrm{CONH}\left(\mathrm{CH}_{2}\right)_{14} \mathrm{CH}_{3}$ & 82 & 169 & $\begin{array}{l}+41.9 \\
(c 1.0)\end{array}$ & $1680,1560,1260,1140$ & $\mathrm{CD}_{3} \mathrm{OD}$ & $0.96\left(3 \mathrm{H}, \mathrm{m}, \mathrm{CH}_{3}\right)$ & - \\
\hline $9 d$ & $\begin{array}{c}(\mathrm{R}, \mathrm{S}) \\
\mathrm{COCH}_{2} \mathrm{CH}\left(\mathrm{CH}_{2}\right)_{6} \mathrm{CH}_{3} \\
\text { OH }\end{array}$ & 46 & 209 & $\begin{array}{l}+74.7 \\
(c 1.0)\end{array}$ & $1630,1560,1140$ & $\mathrm{CD}_{3} \mathrm{OD}$ & $\begin{array}{l}0.96\left(3 \mathrm{H}, \mathrm{m}, \mathrm{CH}_{3}\right), 5.52(1 \mathrm{H}, \\
\mathrm{d}, J=3 \mathrm{~Hz})\end{array}$ & - \\
\hline $9 \mathrm{e}$ & $\begin{array}{c}(R, S) \\
\mathrm{COCH}_{2} \mathrm{CH}\left(\mathrm{CH}_{2}\right)_{12} \mathrm{CH}_{3} \\
\mathrm{OH}\end{array}$ & 22 & 223 & $\begin{array}{l}+533 \\
(c 20)\end{array}$ & $1630,1550,1140$ & $\mathrm{CD}_{3} \mathrm{OD}$ & $\begin{array}{l}0.93\left(3 \mathrm{H}, \mathrm{m}, \mathrm{CH}_{3}\right), 5.50(1 \mathrm{H}, \\
\mathrm{d}, J=3 \mathrm{~Hz})\end{array}$ & - \\
\hline 9f & $\begin{array}{c}(R, S) \\
\mathrm{COCH}_{2} \mathrm{CH}\left(\mathrm{CH}_{2}\right)_{14} \mathrm{CH}_{3} \\
\mathrm{OH}\end{array}$ & 84 & 193 & $\begin{array}{l}+57.2 \\
(c 1.0)\end{array}$ & $1640,1560,1140$ & $\mathrm{CD}_{3} \mathrm{OD}$ & $0.93\left(3 \mathrm{H}, \mathrm{m}, \mathrm{CH}_{3}\right)$ & - \\
\hline
\end{tabular}

a Not measured. 
Table 10. In vitro antiviral activity of $1-N$-palmitoyl- $3^{\prime \prime}-N$-acylkanamycin A derivatives (7).

\begin{tabular}{|c|c|c|c|c|}
\hline \multirow{2}{*}{ No. } & \multirow{2}{*}{$\mathrm{R}^{\prime}$} & \multicolumn{2}{|c|}{ Antiviral activity $\operatorname{ID}_{50}(\mu \mathrm{g} / \mathrm{ml})$} & \multirow{2}{*}{$\begin{array}{l}\text { Cytotoxicity } \\
\text { on Vero cell } \\
(\mu \mathrm{g} / \mathrm{ml})\end{array}$} \\
\hline & & HSV-I & Influenza virus & \\
\hline $7 a$ & $\mathrm{H}$ & 3.2 & 32 & 10 \\
\hline $7 b$ & $\mathrm{CHO}$ & 2.2 & $>10$ & 32 \\
\hline $7 c$ & $\mathrm{COCH}_{3}$ & 1.0 & 22 & 32 \\
\hline $7 d$ & $\mathrm{COCH}_{2} \mathrm{CH}_{3}$ & 1.8 & 22 & 100 \\
\hline $7 e$ & $\mathrm{COCH}_{2} \mathrm{CH}_{2} \mathrm{CH}_{3}$ & 4.8 & $-^{a}$ & 100 \\
\hline $7 f$ & $\mathrm{COCH}\left(\mathrm{CH}_{3}\right)_{2}$ & 1.7 & 63 & 10 \\
\hline $7 g$ & $\mathrm{COCH}_{2} \mathrm{C}\left(\mathrm{CH}_{3}\right)_{3}$ & 3.2 & - & 32 \\
\hline $7 \mathrm{~h}$ & $\mathrm{COC}_{6} \mathrm{H}_{5}$ & 2.8 & 21 & 100 \\
\hline $7 \mathbf{i}$ & $\mathrm{COCH}_{2}$ & 2.7 & $>32$ & 32 \\
\hline $7 \mathbf{j}$ & $\mathrm{COCH}_{2} \mathrm{Cl}$ & 1.9 & - & 100 \\
\hline $7 \mathrm{k}$ & $\begin{array}{c}\mathrm{COCH}_{2} \mathrm{OH} \\
(R, S)\end{array}$ & 2.7 & $>32$ & 32 \\
\hline 71 & $\begin{array}{c}\mathrm{COCHCH}_{3} \\
\mid \mathrm{OH} \\
(R, S)\end{array}$ & 7.8 & $>32$ & 100 \\
\hline $7 \mathrm{~m}$ & $\begin{array}{c}\mathrm{COCH}_{2} \mathrm{CHCH}_{3} \\
\text { OH }\end{array}$ & 4.4 & 56 & 32 \\
\hline $7 n$ & $\mathrm{CONH}_{2}$ & 6.8 & 24 & 32 \\
\hline 70 & $\begin{array}{l}\mathrm{COCH}_{2} \mathrm{NH}_{2} \\
(S)\end{array}$ & 1.0 & 63 & 10 \\
\hline $7 p$ & $\begin{array}{c}\mathrm{COCHCH}_{2} \mathrm{NH}_{2} \\
\mid \\
\mathrm{OH} \\
(S)\end{array}$ & 2.7 & - & 32 \\
\hline $7 q$ & $\begin{array}{c}\mathrm{COCHCH}_{2} \mathrm{CH}_{2} \mathrm{NH}_{2} \\
\mathrm{NH}_{2}\end{array}$ & 8.4 & 32 & 100 \\
\hline $7 r$ & $\mathrm{COCH}_{2} \mathrm{CH}_{2} \mathrm{COOH}$ & 6.0 & - & 32 \\
\hline $7 \mathrm{~s}$ & $\mathrm{COC}_{6} \mathrm{H}_{4} \mathrm{COOH}(o)$ & 6.0 & - & 32 \\
\hline $7 t$ & $\mathrm{COCH}_{2} \mathrm{NHCHO}$ & 2.2 & - & 32 \\
\hline $7 u$ & $\mathrm{COCF}_{3}$ & 1.4 & 16 & $>100$ \\
\hline & Virazole & 32 & 10 & $>100$ \\
\hline & Amantadine & $>100$ & 10 & $>100$ \\
\hline & Acyclovir & 0.032 & $>10$ & $>10$ \\
\hline
\end{tabular}

Assay system: Vero cell, CPE inhibition method.

a Not measured.

Effect of Acyl Group at the $N-3^{\prime \prime}$ Position of 1-N-(3-Hydroxytetradecanoyl)kanamycin A

The antiviral activity and cytotoxicity of the $3^{\prime \prime}-\mathrm{N}$-acylkanamycin A derivatives (8) having 3hydroxytetradecanoyl group at the $N-1$ position are summarized in Table 11.

Antiviral Activity against HSV-I:

The $3^{\prime \prime}-N$-unsubstituted derivative (8a) having 3-hydroxytetradecanoyl group at the $N$-1 position exhibited excellent antiviral activity against HSV-I $\left(\mathrm{ID}_{50} 1.7 \mu \mathrm{g} / \mathrm{ml}\right)$. The activity of $8 \mathrm{a}$ was 4 times more than that of the $3^{\prime \prime}-N$-trifluoroacetyl analog (8d) and was similar to that of the $1-N$-palmitoyl3"- $N$-trifluoroacetylkanamycin A (7u). The $3^{\prime \prime}-N$-glycyl analog (8e) showed remarkable antiviral activity ( $\left.\mathrm{ID}_{50} 3.8 \mu \mathrm{g} / \mathrm{ml}\right)$ and was 2 times less active than $\mathbf{7 u}$. However, analogs $(\mathbf{8 b}, \mathbf{c}, \mathbf{f})$ having formyl, 
Table 11. In vitro antiviral activity of 1-N-(3-hydroxytetradecanoyl)-3"- $N$-acylkanamycin A derivatives (8).

\begin{tabular}{|c|c|c|c|c|}
\hline \multirow{2}{*}{ No. } & \multirow{2}{*}{$\mathrm{R}^{\prime}$} & \multicolumn{2}{|c|}{ Antiviral activity $\mathrm{ID}_{50}(\mu \mathrm{g} / \mathrm{ml})$} & \multirow{2}{*}{$\begin{array}{c}\text { Cytotoxicity } \\
\text { on Vero cell } \\
(\mu \mathrm{g} / \mathrm{ml})\end{array}$} \\
\hline & & HSV-I & Influenza virus & \\
\hline $8 \mathrm{a}$ & $\mathrm{H}$ & 1.7 & $>100$ & 100 \\
\hline $8 \mathrm{~b}$ & $\mathrm{CHO}$ & 13 & $-^{a}$ & $>100$ \\
\hline $8 \mathrm{c}$ & $\mathrm{COCH}_{3}$ & 13 & - & $>100$ \\
\hline $8 \mathrm{~d}$ & $\mathrm{COCF}_{3}$ & 7.9 & - & $>100$ \\
\hline $8 \mathrm{e}$ & $\begin{array}{l}\mathrm{COCH}_{2} \mathrm{NH}_{2} \\
(S)\end{array}$ & 3.8 & $>100$ & 100 \\
\hline \multirow[t]{3}{*}{$8 f$} & $\begin{array}{c}\mathrm{COCHCH} \mathrm{H}_{2} \mathrm{NH}_{2} \\
\quad{ }_{\mathrm{OH}}\end{array}$ & 8.8 & 70 & $>100$ \\
\hline & Virazole & 32 & 10 & $>100$ \\
\hline & Amantadine & $>100$ & 10 & $>100$ \\
\hline
\end{tabular}

Assay system: Vero cell, CPE inhibition method.

a Not measured.

Table 12. In vitro antiviral activity of $1-N$-higher-acyl-3" $-N$-glycylkanamycin A derivatives (9).

\begin{tabular}{|c|c|c|c|c|}
\hline \multirow{2}{*}{ No. } & \multirow{2}{*}{$\mathrm{R}$} & \multicolumn{2}{|c|}{ Antiviral activity $\operatorname{ID}_{50}(\mu \mathrm{g} / \mathrm{ml})$} & \multirow{2}{*}{$\begin{array}{l}\text { Cytotoxicity } \\
\text { on Vero cell } \\
(\mu \mathrm{g} / \mathrm{ml})\end{array}$} \\
\hline & & HSV-I & Influenza virus & \\
\hline $9 \mathrm{a}$ & $\mathrm{CO}\left(\mathrm{CH}_{2}\right)_{13} \mathrm{CH}_{3}$ & 4.0 & 16 & 32 \\
\hline $9 b$ & $\mathrm{COO}\left(\mathrm{CH}_{2}\right)_{15} \mathrm{CH}_{3}$ & 6.2 & 32 & 32 \\
\hline $9 \mathrm{c}$ & $\mathrm{CONH}\left(\mathrm{CH}_{2}\right)_{14} \mathrm{CH}_{3}$ & 5.9 & 60 & 32 \\
\hline 9d & $\begin{array}{c}\mathrm{COCH}_{2} \mathrm{CH}\left(\mathrm{CH}_{2}\right)_{8} \mathrm{CH}_{3} \\
\text { OH }\end{array}$ & $>100$ & $>100$ & $>100$ \\
\hline (8e) & $\begin{array}{c}(R, S) \\
\mathrm{COCH}_{2} \mathrm{CH}\left(\mathrm{CH}_{2}\right)_{10} \mathrm{CH}_{3} \\
\stackrel{\mathrm{OH}}{ }\end{array}$ & 3.8 & $>100$ & 100 \\
\hline $9 \mathrm{e}$ & $\begin{array}{c}(R, S) \\
\mathrm{COCH}_{2} \mathrm{CH}\left(\mathrm{CH}_{2}\right)_{12} \mathrm{CH}_{3} \\
\mathrm{OH} \\
\text { OH }\end{array}$ & 3.7 & 25 & 32 \\
\hline \multirow[t]{3}{*}{ 9f } & $\begin{array}{c}\mathrm{COCH}_{2} \mathrm{CH}\left(\mathrm{CH}_{2}\right)_{14} \mathrm{CH}_{3} \\
\text { OH }\end{array}$ & 2.4 & $>10$ & 32 \\
\hline & Virazole & 32 & 10 & $>100$ \\
\hline & Amantadine & $>100$ & 10 & $>100$ \\
\hline
\end{tabular}

Assay system: Vero cell, CPE inhibition method.

acetyl, or 3-amino-2-hydroxypropionyl group exhibited less weak antiviral activity and were about 10 times less active than that of $7 \mathrm{u}$.

Antiviral Activity against Influenza Virus:

The analogs $(\mathbf{8} \mathbf{a} \sim \mathbf{f})$ described above exhibited little or no antiviral activity against infiuenza virus in contrast with antiviral activity against HSV-I.

The cytotoxicity of 8 was more than $100 \mu \mathrm{g} / \mathrm{ml}$ similarly to that of $7 \mathrm{u}$.

Effect of Higher-acyl Group at the $N-1$ Position of $3^{\prime \prime}-N$-Glycylkanamycin A

The antiviral activity and cytotoxicity of the $3^{\prime \prime}-N$-glycylkanamycin A derivatives (9) having a higher acyl group at the $N-1$ position are summarized in Table 12 . 
Antiviral Activity against HSV-I:

The 1- $N$-pentadecanoyl (9a), 1- $N$-hexadecanyloxycarbonyl (9b), and 1- $N$-pentadecanylaminocarbonyl derivatives (9c) having glycyl group at the $N-3^{\prime \prime}$ position exhibited strong antiviral activity against HSV-I (ID ${ }_{50} 1.2 \sim 1.8 \mu \mathrm{g} / \mathrm{ml}$ ) and were about 30 times more active than virazole. The 1- $N$-(3-hydroxytetradecanoyl) (8e), 1-N-(3-hydroxyhexadecanoyl) (9e), and 1-N-(3-hydroxyoctadecanoyl) (9f) derivatives also showed excellent antiviral activity against HSV-I ( $\left.\operatorname{ID}_{50} 1.1 \sim 2.7 \mu \mathrm{g} / \mathrm{ml}\right)$. However, the 1- $N$-(3-hydroxydecanoyl) derivative (9d) exhibited no antiviral activity.

The cytotoxicity of these derivatives (9) was slightly stronger than that of $7 u$.

Antiviral Activity against Influenza Virus:

The 1-N-pentadecanoyl derivative (9a) having glycyl group at the $N-3^{\prime \prime}$ position exhibited strong antiviral activity against influenza virus ( $\operatorname{ID}_{50} 5 \mu \mathrm{g} / \mathrm{ml}$ ). The derivative (9a) was 2 times more active than amantadine and virazole and was 3 times more active than the $1-N$-palmitoyl- $3^{\prime \prime}-N$-trifluoroacetylkanamycin A (7u). The 3"- $N$-glycylkanamycin A derivatives (9e, f) having 3-hydroxyhexadecanoyl or 3-hydroxyoctadecanoyl group at the $N$-1 position showed similar antiviral activity against influenza virus to the derivative ( $7 \mathrm{u})$.

\section{Discussion}

In this series, the 1-N-palmitoyl-3"- $N$-unsubstituted (7a) and 1- $N$-pentadecanoyl-3" $-N$-glycyl (9a) derivatives exhibited excellent antiviral activity against not only HSV-I but also influenza virus, and were also soluble in water $(>0.1 \mathrm{mg} / \mathrm{ml})$ at around neutral $\mathrm{pH}$. Further, the derivatives $(7 \mathrm{~g} \sim \mathbf{i})$ having a bulky acyl group at the $N-3^{\prime \prime}$ position showed remarkable antiviral activity against HSV-I, but tended to decrease antiviral activity against influenza virus. On the basis of these results, the acyl group at the $\mathrm{N}-3^{\prime \prime}$ position was not essential to give rise to the strong antiviral activity. The balance between lipophilic and hydrophilic character in the kanamycin A molecule might be assumed to be one of important factors for the emergence of antiviral activity, because the lipophilic kanamycin A molecule could penetrate through the cell membrane infected by virus and inhibit certain stages of virus protein synthesis. Mechanism of the growth inhibition of virus is now under investigation.

\section{Experimental}

The spectrometric data were obtained by the following instruments. Melting points were determined using Yanagimoto micro melting point apparatus and are uncorrected. NMR spectra were recorded at $60 \mathrm{MHz}$ on a JNM-PMX $60 \mathrm{NMR}$ spectrometer and at $100 \mathrm{MHz}$ on a Jeol-MH 100 NMR spectrometer using $\mathrm{Me}_{4} \mathrm{Si}$ as an internal standard. IR spectra were taken on a Hitachi 260-10 spectrophotometer. Optical rotations were determined with Jasco DIP-140 polarimeter. FD-Mass spectra were measured on Jeol-D 300 mass spectrometer.

Assay

Assays were carried out in confiuent Vero cell cultures in multi-well trays ( 96 wells). The cell cultures were grown to confluence in EAGLE's minimal essential medium (MEM) supplemented with $5 \%$ fetal bovine serum (FBS). HSV-I Miyama and influenza virus A/PR 8 were respectively grown in Vero cells and Madin and Darby canine kidney cells (MDCK cells). The culture medium was changed to $0.5 \%$ FBS-MEM. The cell cultures were inoculated with about 100 times the virus dose needed to infect 50 percent of cells $\left(\right.$ TCID $_{50}$ ) of virus, and immediately thereafter, exposed to varying concentrations of the test compound and incubated for 2 days at $37^{\circ} \mathrm{C}$ in humidified $5 \% \mathrm{CO}_{2}-95 \%$ air. 4 wells (multi-well trays ( 96 wells)) were used in each concentrations. They were fixed with $5 \%$ trichloroacetic acid stained with $0.1 \%$ crystal violet. The viral maximal cytopathic effect (CPE) was observed microscopically $(\times 40)$. Antiviral activity was expressed as $\operatorname{ID}_{50}(50 \%$ inhibitory dose), 
that is, the concentration of compound required to reduce viral CPE by $50 \%$ (within the well), when it had reached completion ( $100 \%$ cell destruction) in the control virus-infected cell cultures.

\section{Cytotoxicity}

In tests which were run in parallel with the antiviral assays in confluent Vero cell cultures (which had not been infected), the compounds were examined for their effects on normal cell morphology. The cytotoxicity was expressed as the minimum concentration of drug which destroyed the cell monolayer.

\section{Material}

3,6'-Bis ( $N$-benzyloxycarbonyl)- $3^{\prime \prime}-N$-trifluoroacetylkanamycin A (2): The compound (2) was synthesized according to the method of TsuchiYa et al. ${ }^{3}$.

General Procedure for Acylation of $\mathbf{2}$

$1-N$-Acyl-3, $6^{\prime}$-bis( $N$-benzyloxycarbonyl)-3" $-N$-trifluoroacetylkanamycin A Derivatives (3): These derivatives (3) were obtained according to a similar manner to that of acylation of 2 described in the previous paper ${ }^{2)}$ (Table 1).

\section{General Procedure for Acylation of $\mathbf{3}$}

To a solution of $3(1.97 \mathrm{mmol})$ in pyridine $(40 \mathrm{ml})$ was added acetic anhydride $(25.6 \mathrm{mmol})$ at room temperature. The mixture was stirred at $50^{\circ} \mathrm{C}$ for 5 hours and allowed to stand at room temperature overnight. The reaction mixture was concentrated under reduced pressure. A solution of the residue in EtOAc $(100 \mathrm{ml})$ was washed with $1 \mathrm{~N} \mathrm{HCl}$, saturated aqueous $\mathrm{NaHCO}_{3}$, and saturated aqueous $\mathrm{NaCl}$ successively, dried over anhydrous $\mathrm{MgSO}_{4}$, and evaporated in vacuo to afford $2^{\prime}, 3^{\prime}, 4^{\prime}, 2^{\prime \prime}, 4^{\prime \prime}, 6^{\prime \prime}$ hexa- $O$-acetyl-1- $N$-acyl-3, $6^{\prime}$-bis( $N$-benzyloxycarbonyl)-3" $-N$-trifluoroacetylkanamycin A derivatives (4) as a glass in good yields (Table 2).

\section{General Procedure for Deacetylation and Detrifluoroacetylation of 4}

To a solution of potassium hydroxide $(\mathrm{KOH})(24.9 \mathrm{mmol})$ in $\mathrm{MeOH}(50 \mathrm{ml})$ was added the derivative $(4,1.78 \mathrm{mmol})$ at room temperature and the mixture was stirred at the same temperature overnight. The reaction mixture was poured into ice-water $(250 \mathrm{ml})$. The resultant precipitates were collected by filtration, washed with water, and dried to give the 1-N-acyl-3, $6^{\prime}$-bis( $N$-benzyloxycarbonyl)kanamycin A derivatives (5) in good yields (Table 3).

\section{General Procedure for Acylation of 5}

Method A; Acylation with Acid Chloride: To a solution of $5(32.0 \mathrm{mmol})$ in a mixture of tetrahydrofuran (THF) $(600 \mathrm{ml})$ and water $(150 \mathrm{ml})$ was added carboxylic acid chloride $(37.4 \mathrm{mmol})$ with stirring under ice-cooling. The mixture was stirred at the same condition for 1 hour. The reaction mixture was concentrated under reduced pressure to give a suspension. The resultant precipitates were collected by filtration, washed in turn with $1 \mathrm{~N} \mathrm{HCl}(500 \mathrm{ml}), \mathrm{Et}_{2} \mathrm{O}$, iso-propyl alcohol (IPA), and water, and dried to give the 1- $N$-higher-acyl-3"- $N$-acyl-3,6'-bis $(N$-benzyloxycarbonyl)kanamycin A derivatives $(6 \mathrm{D} \sim \mathbf{F}, \mathbf{H}, \mathbf{J})$ as a solid in good yields (Table 4).

Method B; Acylation with Carboxylic Acid: Phosphorous oxychloride ( $3.16 \mathrm{mmol})$ was added to a mixture of dimethylformamide (DMF) $(3.16 \mathrm{mmol})$ and THF $(0.5 \mathrm{ml})$ at $-10 \sim 0^{\circ} \mathrm{C}$ and the suspension was stirred at $-5 \sim 0^{\circ} \mathrm{C}$ for 10 minutes. To the above suspension were added a solution of carboxylic acid $(3.16 \mathrm{mmol})$ in dry THF $(5 \mathrm{ml})$ at the same temperature under stirring and the mixture was stirred for 30 minutes to prepare an activated acid solution. To a solution of $\mathbf{5}(1.59 \mathrm{mmol})$ in a mixture of THF $(40 \mathrm{ml})$ and water $(10 \mathrm{ml})$ was dropwise added the activated acid solution obtained above, keeping the $\mathrm{pH} 8 \sim 9$ with $\mathrm{Et}_{3} \mathrm{~N}$ under ice-cooling. The reaction mixture was stirred for 1 hour at the same condition and concentrated under reduced pressure to give a solid. The solid was washed successively with $1 \mathrm{~N} \mathrm{HCl}, \mathrm{Et}_{2} \mathrm{O}$, and water and dried to give the $1-N$-higher-acyl-3"- $N$-acyl$3,6^{\prime}$-bis $(N$-benzyloxycarbonyl)kanamycin A $(6 \mathbf{G}, \mathbf{Y}, \mathbf{a}, \mathbf{d}, \mathbf{e}, \mathbf{f})$ as a solid in good yields (Tables 4,5 and 6).

Method C; Acylation with $N$-(Acyloxy)succinimide: To a solution of $5(1.00 \mathrm{mmol})$ in dimethyl 
sulfoxide (DMSO) $(20 \mathrm{ml})$ were added $N$-(acyloxy)succinimide $(2.04 \mathrm{mmol})$ and $\mathrm{Et}_{3} \mathrm{~N}(0.3 \mathrm{ml})$ at room temperature and the mixture was stirred at the same temperature overnight. The reaction mixture was dropwise added to $\mathrm{Et}_{2} \mathrm{O}(200 \mathrm{ml})$. The resultant precipitates were collected by filtration, washed with $\mathrm{Et}_{2} \mathrm{O}$ and water successively, and dried to give $1-N$-higher-acyl-3" $3^{\prime \prime} N$-acyl-3,6'-bis $(N$-benzyloxycarbonyl)kanamycin A $(\mathbf{6 I}, \mathbf{L}, \mathbf{M}, \mathbf{P}, \mathbf{Q}, \mathbf{T}, \mathbf{Z})$ as a solid in good yields. Their physical data and yields are summarized in Tables 4 and 5 .

3,6'-Bis( $N$-benzyloxycarbonyl)-3"'-N-(benzyloxycarbonyl)aminocarbonyl-1- $N$-palmitoylkanamycin $\mathrm{A}(6 \mathrm{~N})$

To a solution of $\mathbf{5 b}(1.0 \mathrm{~g})$ in dry THF $(20 \mathrm{ml})$ was added benzyloxycarbonyl isocyanate $(0.21 \mathrm{~g})$ at room temperature overnight. The reaction mixture was concentrated under reduced pressure to give a solid. The solid was collected by filtration, washed with water and $\mathrm{Et}_{2} \mathrm{O}$ successively, and dried to give $6 \mathbf{N}$ as a solid in a good yield (Table 4).

General Procedure for Formylation of $\mathbf{5}$ with $p$-Nitrophenyl Formate

To a solution of $5(0.5 \mathrm{mmol})$ in a mixture of DMF $(10 \mathrm{ml})$ and water $(2 \mathrm{ml})$ were added $p$-nitrophenyl formate $(1.5 \mathrm{mmol})$ and $\mathrm{Et}_{3} \mathrm{~N}(0.08 \mathrm{ml})$ and the mixture was stirred for 2 hours. The reaction mixture was dropwise added to $\mathrm{Et}_{2} \mathrm{O}(200 \mathrm{ml})$. The resultant precipitates were collected by filtration, washed with $\mathrm{Et}_{2} \mathrm{O}$, and dried to give 3,6'-bis( $N$-benzyloxycarbonyl)-3" $-N$-formyl-1- $N$-palmitoyl-, or $-1-N-(3-h y d r o x y t e t r a d e c a n o y l) k a n a m y c i n ~ A(6 B, V)$ as a solid in good yields (Tables 4 and 5).

3,6'-Bis( $N$-benzyloxycarbonyl)-1- $N$-palmitoyl-3"'- $N$-phthalylkanamycin A (6S)

To a solution of $\mathbf{5 b}(0.5 \mathrm{~g})$ in DMSO $(10 \mathrm{ml})$ were successively added $N$-(ethoxycarbonyl)phthalimide $(122 \mathrm{mg})$ and $\mathrm{Et}_{3} \mathrm{~N}(0.08 \mathrm{ml})$ at room temperature. The mixture was stirred at the same temperature for 3 hours. The reaction mixture was poured into $\mathrm{Et}_{2} \mathrm{O}(200 \mathrm{ml})$ to give a residue, which was twice washed with $\mathrm{Et}_{2} \mathrm{O}(200 \mathrm{ml})$. The resultant precipitates were collected by filtration and dried. The solid was subjected to column chromatography on silica gel $(30 \mathrm{~g})$ and eluted with a mixture of $\mathrm{CHCl}_{3}$ $\mathrm{MeOH}(10: 1)$. The fractions containing the desired compound were combined and concentrated under reduced pressure to give $6 \mathrm{~S}(0.12 \mathrm{~g})$ as a solid (Table 4).

\section{$3,6^{\prime}$-Bis( $N$-benzyloxycarbonyl)-1-N-(3-hydroxytetradecanoyl) $-3^{\prime \prime}-N$-trifluoroacetylkanamycin A (6X)}

To a solution of $5 \mathrm{~d}(800 \mathrm{mg})$ in DMF $(8 \mathrm{ml})$ was added a solution of ethyl trifluoroacetate $(127 \mathrm{mg})$ in DMSO $(1 \mathrm{ml})$ at room temperature and the mixture was stirred at the same temperature for 2 hours. The reaction mixture was poured into ice-water $(80 \mathrm{ml})$. The resultant precipitates were collected by filtration, washed successively with water $(60 \mathrm{ml})$ and a mixture of IPA $(20 \mathrm{ml})$ and $\mathrm{Et}_{2} \mathrm{O}(20 \mathrm{ml})$, and dried to give $6 \mathbf{X}$ as a solid $(777 \mathrm{mg}$ ) (Table 5).

\section{3,6'-Bis( $N$-benzyloxycarbonyl)-3"- $N$-(3-carboxypropionyl)-1- $N$-palmitoylkanamycin A (6R)}

To a solution of $\mathbf{5 b}(0.5 \mathrm{~g})$ in a mixture of THF $(40 \mathrm{ml})$ and water $(10 \mathrm{ml})$ was added succinic anhydride $(0.06 \mathrm{~g})$ and the mixture was stirred at room temperature for 3.5 hours. The reaction mixture was concentrated under reduced pressure to give a solid, which was collected by filtration, washed with water and $\mathrm{Et}_{2} \mathrm{O}$ successively, and dried to give $6 \mathrm{R}(0.55 \mathrm{~g})$ as a solid (Table 4$)$.

3,6'-Bis( $N$-benzyloxycarbonyl)-1- $N$-(tert-butoxycarbonyl)kanamycin A (10)

To a solution of $2(3 \mathrm{~g})$ in a mixture of THF $(48 \mathrm{ml})$ and water $(12 \mathrm{ml})$ were added 2-tert-butoxycarbonyloximino-2-phenylacetonitrile $(1.04 \mathrm{~g})$ and $\mathrm{Et}_{3} \mathrm{~N}(0.59 \mathrm{ml})$ at room temperature and the mixture was stirred at the same temperature for 2 hours. Furthermore, 2-tert-butoxycarbonyloximino-2phenylacetonitrile $(1.04 \mathrm{~g})$ and $\mathrm{Et}_{3} \mathrm{~N}(0.59 \mathrm{ml})$ were added to the solution and the mixture was stirred at room temperature overnight. The solution was concentrated under reduced pressure to give a crude solid (12 g).

A solution of the solid $(12 \mathrm{~g})$ in a mixture of DMF $(50 \mathrm{ml})$ and conc $\mathrm{NH}_{4} \mathrm{OH}(25 \mathrm{ml})$ was stirred at room temperature overnight. Further, conc $\mathrm{NH}_{4} \mathrm{OH}(30 \mathrm{ml})$ was added to the solution and the mixture was stirred at room temperature for 8 hours. The reaction mixture was poured into $\mathrm{Et}_{2} \mathrm{O}$ 
$(500 \mathrm{ml})$ and resultant precipitates were collected by filtration, washed with $\mathrm{Et}_{2} \mathrm{O}(100 \mathrm{ml})$ and water $(100 \mathrm{ml})$ successively, and dried to give $10(2.5 \mathrm{~g}, 82.9 \%)$ as a solid. MP $246 \sim 247^{\circ} \mathrm{C}$; IR (Nujol) 1685,1670 (sh), 1650, 1520, $1270 \mathrm{~cm}^{-1}$; NMR (DMSO- $\left.d_{6}, \delta\right) 1.36\left(9 \mathrm{H}, \mathrm{s},\left(\mathrm{CH}_{3}\right)_{3} \mathrm{C}\right)$.

$3,6^{\prime}$-Bis $(N$-benzyloxycarbonyl) - 3" $-N$ - [N-(benzyloxycarbonyl)glycyl] $-1-N$-(tert-butoxycarbonyl)kanamycin A (11a)

Phosphorous oxychloride $(0.56 \mathrm{ml})$ was added to a mixture of DMF $(0.47 \mathrm{ml})$ and THF $(0.9 \mathrm{ml})$ and the suspension was stirred at $-5 \sim 0^{\circ} \mathrm{C}$ for 10 minutes. To the above suspension was added a solution of $N$-(benzyloxycarbonyl)glycine $(0.98 \mathrm{~g})$ in THF $(9 \mathrm{ml})$ at the same temperature under stirring and the solution was stirred for 30 minutes to prepare an activated acid solution. To a solution of $\mathbf{1 0}$ $(2 \mathrm{~g})$ in a mixture of THF $(60 \mathrm{ml})$ and water $(15 \mathrm{ml})$ was dropwise added the activated acid solution obtained above, keeping the $\mathrm{pH} 8 \sim 9$ with $\mathrm{Et}_{3} \mathrm{~N}$. The reaction mixture was stirred at the same temperature for 30 minutes and was concentrated under reduced pressure to give a suspension. The resultant solid was collected by filtration, washed in turn with $1 \mathrm{~N} \mathrm{HCl}, \mathrm{Et}_{2} \mathrm{O}$, water, and a mixture of $\mathrm{Et}_{2} \mathrm{O}$ - IPA (1: 1), and dried to give $11 \mathrm{a}\left(1.91 \mathrm{~g}, 78 \%\right.$ ) as a solid. MP $148 \sim 150^{\circ} \mathrm{C}$; IR (Nujol) 1680 , $1520,1260,1150 \mathrm{~cm}^{-1}$; NMR (DMSO- $\left.d_{6}, \delta\right) 1.35\left(9 \mathrm{H}, \mathrm{s},\left(\mathrm{CH}_{3}\right)_{3} \mathrm{C}\right)$.

$3^{\prime \prime}-N$-(Benzyloxyacetyl) $-3,6^{\prime}-$ bis( $N$-benzyloxycarbonyl) $-1-N$-(tert-butoxycarbonyl)kanamycin A (11b)

The compound (11b) was obtained according to a similar manner to that of 11a.

IR (Nujol) 1680, $1520 \mathrm{~cm}^{-1}$; NMR (DMSO-d $\left.d_{6}, \delta\right) 1.37\left(9 \mathrm{H}, \mathrm{s},\left(\mathrm{CH}_{3}\right)_{3} \mathrm{C}\right), 4.57\left(2 \mathrm{H}, \mathrm{s}, \mathrm{CH}_{2}\right)$.

3"- $N$-Acetyl-3,6'-bis( $N$-benzyloxycarbonyl)-1- $N$-(tert-butoxycarbonyl)kanamycin A (11c)

To a solution of $\mathbf{1 0}(2 \mathrm{~g})$ in a mixture of THF $(40 \mathrm{ml})$ and water $(10 \mathrm{ml})$, acetyl chloride $(0.22 \mathrm{~g})$ was dropwise added with stirring at room temperature, keeping the $\mathrm{pH} 8 \sim 8.5$ with $\mathrm{Et}_{3} \mathrm{~N}$. The solution was stirred under the same condition for 1 hour. The resultant precipitates were collected by filtration, washed three times with $\mathrm{Et}_{2} \mathrm{O}(20 \mathrm{ml})$ and water $(60 \mathrm{ml})$ in turn, and dried to give 11c as a solid $\left(1.86 \mathrm{~g}, 89 \%\right.$ ). MP $236^{\circ} \mathrm{C}$ (dec); IR (Nujol) $1680,1510,1500,1140,1030 \mathrm{~cm}^{-1}$; NMR (DMSO$\left.d_{6}, \delta\right) 1.85\left(3 \mathrm{H}, \mathrm{s}, \mathrm{CH}_{3} \mathrm{CO}\right)$.

$3^{\prime \prime}-N$-Acetyl-3,6'-bis( $N$-benzyloxycarbonyl)-1- $N$-palmitoylkanamycin A (6C)

A solution of $11 \mathrm{c}(1.8 \mathrm{~g})$ in a mixture of TFA $(20 \mathrm{ml})$ and anisole $(5 \mathrm{ml})$ was stirred under ice-cooling for 1 hour. The solution was concentrated under reduced pressure to give a residue, which was dissolved in a mixture of THF $(60 \mathrm{ml})$ and water $(15 \mathrm{ml})$. To the resultant solution was dropwise added palmitoyl chloride $(0.58 \mathrm{~g})$ with stirring at $0 \sim 5^{\circ} \mathrm{C}$, keeping the $\mathrm{pH} 8 \sim 8.5$ with $\mathrm{Et}_{3} \mathrm{~N}$. The mixture was stirred under the same condition for 1 hour and the reaction mixture was concentrated under reduced pressure. The resultant solid was washed in turn with water, $1 \mathrm{~N} \mathrm{HCl}, \mathrm{Et}_{2} \mathrm{O}$, and water. The solid was dried to give $6 \mathrm{C}(1.96 \mathrm{~g}, 98 \%$ ) (Table 4$)$.

\section{$3^{\prime \prime}-N$-(Benzyloxyacetyl)-3,6'-bis( $N$-benzyloxycarbonyl)-1- $N$-palmitoylkanamycin A (6K)}

To a suspension of $11 \mathbf{b}(0.95 \mathrm{~g})$ in anisole $(2.9 \mathrm{ml})$ was added TFA $(9.5 \mathrm{ml})$ under ice-cooling. The mixture was stirred at the same temperature for 2 hours and concentrated under reduced pressure to give a syrup. The syrup was dissolved in a mixture of THF $(30 \mathrm{ml})$ and water $(7 \mathrm{ml})$, and to the mixture was added palmitoyl chloride $\left(265 \mathrm{mg}\right.$ ) under ice-cooling, keeping the $\mathrm{pH} 8 \sim 9$ with $\mathrm{Et}_{3} \mathrm{~N}$. The mixture was stirred under the same condition for 2 hours. The reaction mixture was concentrated under reduced pressure. The resultant precipitates were collected by filtration, washed with water, $1 \mathrm{~N} \mathrm{HCl}$, water, and $\mathrm{Et}_{2} \mathrm{O}$ in turn, and dried to give $6 \mathrm{~K}(1.05 \mathrm{~g}, 99 \%)$ (Table 4).

$3,6^{\prime}$-Bis( $N$-benzyloxycarbonyl) - 3" $-N$-[N-(benzyloxycarbonyl)glycyl $]-1-N$-palmitoylkanamycin A $(6 \mathrm{O})$

A solution of $11 \mathrm{a}(0.92 \mathrm{~g})$ in a mixture of TFA $(10 \mathrm{ml})$ and anisole $(3 \mathrm{ml})$ was stirred under icecooling for 1 hour. The solution was concentrated under reduced pressure. To a solution of the resultant residue in a mixture of THF $(40 \mathrm{ml})$ and water $(10 \mathrm{ml})$ was dropwise added a solution of palmitoyl chloride $(254 \mathrm{mg})$ in $\mathrm{THF}(10 \mathrm{ml})$ at $0 \sim 5^{\circ} \mathrm{C}$ with stirring, keeping the $\mathrm{pH} 8 \sim 9$ with $\mathrm{Et}_{3} \mathrm{~N}$. 
The mixture was stirred at the same temperature for 1 hour and the reaction mixture was concentrated under reduced pressure to give a solid. The solid was washed with $1 \mathrm{~N} \mathrm{HCl}(20 \mathrm{ml}), \mathrm{IPA}(20 \mathrm{ml})$, $\mathrm{Et}_{2} \mathrm{O}(10 \mathrm{ml})$, and water in turn and dried to give $6 \mathrm{O}(0.91 \mathrm{~g}, 87 \%$ ) (Table 4$)$.

\section{3"'-N-Acetyl-3,6'-bis ( $N$-benzyloxycarbonyl)-1- $N$-(3-hydroxytetradecanoyl)kanamycin A (6W)}

To a solution of $\mathbf{1 0}(2 \mathrm{~g})$ in pyridine $(40 \mathrm{ml})$ was added acetic anhydride $(3.1 \mathrm{ml})$. The mixture was stirred at room temperature for 3 hours and allowed to stand at the same temperature overnight. The reaction mixture was concentrated under reduced pressure. The residue was dissolved in EtOAc $(100 \mathrm{ml})$ and the solution was washed with aqueous $\mathrm{NaHCO}_{3}$ and water successively, dried over anhydrous $\mathrm{Na}_{2} \mathrm{SO}_{4}$, and concentrated under reduced pressure to give $2^{\prime}, 3^{\prime}, 4^{\prime}, 2^{\prime \prime}, 4^{\prime \prime}, 6^{\prime \prime}$-hexa-O-acetyl-3"$N$-acetyl-3,6'-bis( $N$-benzyloxycarbonyl)-1- $N$-(tert-butoxycarbonyl)kanamycin A $(2.54 \mathrm{~g}, 97.1 \%)$ as an amorphous solid. IR (Nujol) $1740,1520,1240,1170 \mathrm{~cm}^{-1}$; NMR $\left(\mathrm{CDCl}_{3}, \delta\right) 1.32\left(9 \mathrm{H}, \mathrm{s},\left(\mathrm{CH}_{3}\right)_{3} \mathrm{C}\right)$, $1.90 \sim 2.20\left(21 \mathrm{H}, \mathrm{m}, \mathrm{CH}_{3} \mathrm{CO}\right)$.

A solution of the compound obtained above $(2.5 \mathrm{~g})$ in a mixture of TFA $(30 \mathrm{ml})$ and anisole $(7 \mathrm{ml})$ was stirred under ice-cooling for 1 hour. The reaction mixture was concentrated in vacuo to give a crude $2^{\prime}, 3^{\prime}, 4^{\prime}, 2^{\prime \prime}, 4^{\prime \prime}, 6^{\prime \prime}$-hexa- $O$-acetyl-3"' $N$-acetyl-3, $6^{\prime}$-bis $(N$-benzyloxycarbonyl)kanamycin A monotrifluoroacetate. Phosphorous oxychloride $(0.29 \mathrm{ml})$ was added to a mixture of DMF $(0.25 \mathrm{ml})$ and THF $(0.5 \mathrm{ml})$ at $-5 \sim 0^{\circ} \mathrm{C}$. To the resultant suspension were added successively THF $(5 \mathrm{ml})$ and 3acetoxytetradecanoic acid $(706 \mathrm{mg})$ at $-5 \sim 0^{\circ} \mathrm{C}$ under stirring. The mixture was stirred at the same temperature for 30 minutes to prepare an activated acid solution. To a solution of the compound obtained above in a mixture of THF $(40 \mathrm{ml})$ and water $(10 \mathrm{ml})$ was dropwise added the activated acid solution, keeping the $\mathrm{pH} 8 \sim 9$ with $\mathrm{Et}_{3} \mathrm{~N}$. The mixture was concentrated under reduced pressure. The residue was dissolved in EtOAc $(120 \mathrm{ml})$. The solution was washed with aqueous $\mathrm{NaHCO}_{3}$ and water in turn, dried over anhydrous $\mathrm{Na}_{2} \mathrm{SO}_{4}$, and concentrated under reduced pressure. The residue was subjected to column chromatography on silica gel $(50 \mathrm{~g})$ and eluted with a mixture of $\mathrm{CHCl}_{3}$ $\mathrm{MeOH}(30: 1)$ to give $1-N$-(3-acetoxytetradecanoyl)-2', $3^{\prime}, 4^{\prime}, 2^{\prime \prime}, 4^{\prime \prime}, 6^{\prime \prime}$-hexa- $O$-acetyl-3"' $N$-acetyl-3, $6^{\prime}$-bis( $N$-benzyloxycarbonyl)kanamycin A $(1.95 \mathrm{~g}, 67.9 \%$ ). IR (Nujol) 3270, 1720 1700, 1650, 1530 1510 $\mathrm{cm}^{-1}$; NMR $\left(\mathrm{CDCl}_{3}, \delta\right) 0.88\left(3 \mathrm{H}\right.$, br s, $\left.\mathrm{CH}_{3}\right)$. Furthermore, to a solution of $\mathrm{KOH}(1.16 \mathrm{~g})$ in $\mathrm{MeOH}$ $(40 \mathrm{ml})$ was added the compound $(1.9 \mathrm{~g})$ and the mixture was stirred at room temperature for 3 hours. The resultant suspension was poured into ice-water $(200 \mathrm{ml})$. The resultant precipitates were collected by filtration, washed with water, and dried to give $6 \mathrm{~W}$ as a solid $(1.20 \mathrm{~g})$ (Table 5).

3,6'-Bis( $N$-benzyloxycarbonyl)-3"' $N$-[( $N$-benzyloxycarbonyl)glycyl]-1- $N$-(hexadecanyloxycarbonyl)kanamycin A (6b)

A solution of $11 \mathrm{a}(1.0 \mathrm{~g})$ in a mixture of TFA $(10 \mathrm{ml})$ and anisole $(3 \mathrm{ml})$ was stirred under ice-cooling for 1 hour. The solution was concentrated under reduced pressure to give a residue. To a solution of the residue $(1 \mathrm{~g})$ in a mixture of THF $(25 \mathrm{ml})$ and water $(5 \mathrm{ml})$ was dropwise added hexadecanyloxycarbonyl chloride $\left(532 \mathrm{mg}\right.$ ) with stirring under ice-cooling, keeping the pH $8 \sim 9$ with $\mathrm{Et}_{3} \mathrm{~N}$. The mixture was stirred at the same temperature for 1 hour. The reaction mixture was evaporated in vacuo to give a solid. The solid was collected by filtration, washed with $1 \mathrm{~N} \mathrm{HCl}$, water, and $\mathrm{Et}_{2} \mathrm{O}$, successively, and dried to give $6 \mathrm{~b}(0.65 \mathrm{~g}, 57 \%)$ as a solid (Table 6$)$.

$3,6^{\prime}$ - Bis $\left(N\right.$ - benzyloxycarbonyl) - $3^{\prime \prime}-N-[(N$-benzyloxycarbonyl)glycyl $]-1-N$-(pentadecanylaminocarbonyl)kanamycin A (6c)

A solution of 11a $(1.9 \mathrm{~g})$ in a mixture of TFA $(20 \mathrm{ml})$ and anisole $(6 \mathrm{ml})$ was stirred under icecooling for 1 hour. The solution was evaporated in vacuo and a solution of the residue in $\mathrm{MeOH}$ $(20 \mathrm{ml})$ was adjusted to $\mathrm{pH} 8 \sim 9$ with aqueous solution of $\mathrm{Na}_{2} \mathrm{CO}_{3}$. The mixture was poured into water $(50 \mathrm{ml})$. The resultant precipitates were collected by filtration, washed with water, and dried. To a solution of the solid $(1.0 \mathrm{~g})$ in DMF $(20 \mathrm{ml})$ was added pentadecanyl isocyanate $(400 \mathrm{mg})$ at room temperature and the mixture was stirred at the same temperature overnight. Furthermore, to the mixture were added $\mathrm{Et}_{3} \mathrm{~N}(0.2 \mathrm{ml})$ and pentadecanyl isocyanate $(400 \mathrm{mg})$ and the mixture was stirred at $30 \sim 40^{\circ} \mathrm{C}$ for 6 hours. The reaction mixture was filtered off and the filtrate was poured into $\mathrm{Et}_{2} \mathrm{O}$ (1 liter). The resultant precipitates were collected by filtration, washed with water $(30 \mathrm{ml})$, and dried 
to give $\mathbf{6 c}(0.69 \mathrm{~g})$ as a solid (Table 6).

General Procedure for Deprotection of 6

A solution of the derivatives $(6 \mathrm{~A} \sim \mathbf{Z}, \mathbf{a} \sim \mathbf{f}: 1.3 \mathrm{mmol})$ in a mixture of THF $(30 \mathrm{ml}), \mathrm{MeOH}(10 \mathrm{ml})$, and $1 \mathrm{~N} \mathrm{HCl}(10 \mathrm{ml})$ was hydrogenated under atomospheric pressure of hydrogen at room temperature for 6 hours in the presence of $10 \%$ palladium on carbon $(1.5 \mathrm{~g})$. The catalyst was filtered off and the filtrate was evaporated in vacuo to give a residue. The solution of the residue in water $(40 \mathrm{ml})$ was filtered off and lyophilized to give 1-N-higher-acyl-3" $-N$-acylkanamycin A derivative hydrochlorides $(\mathbf{7}, \mathbf{8}, \mathbf{9})$ as a hygroscopic solid. Their physical data and yields are summarized in Tables 7,8 and 9.

\section{Acknowledgment}

We are grateful to Drs. Y. Mine and Y. WATANABE for providing the biological data and their suggestion.

\section{References}

1) Matsuda, K.; N. Yasuda, H. Tsutsumi \& T. Takaya: Studies on antiviral agents. I. Synthesis and in vitro antiviral activity of new kanamycin A derivatives. J. Antibiotics 38: 547 549, 1985

2) Matsuda, K.; N. Yasuda, H. Tsutsumi \& T. Takaya: Studies on antiviral agents. II. Synthesis and in vitro antiviral activity on new kanamycin A derivatives having higher acyl group at $N-1$ position. J. Antibiotics 38: 1050 1060, 1985

3) TsuchiYA, T.; Y. TAKAgi \& S. UmezAwA: 1-N-Acylation of aminocyclitol antibiotics via zinc chelation and regiospecific $N$-trifluoroacetylation. Tetrahedron Lett. 1975: 4951 4954, 1975

4) Sidwell, R. W.; J. H. Huffman, G. P. Khare, L. B. Allen, J. T. Witkowski \& R. K. Robins: Broadspectrum antiviral activity of virazole: 1- $\beta$-D-Ribofuranosyl-1,2,4-triazole-3-carboxamide. Science 177: $705 \sim 706,1972$

5) Elion, G. B.; P. A. Furman, J. A. Fyfe, P. Miranda, L. Beauchamp \& H. J. Schaeffer: Selectivity of action of an antiherpetic agent, 9-(2-hydroxyethoxymethyl)guanine. Proc. Natl. Acad. Sci. U.S.A. 74: 5716 5720, 1977

6) Davies, W. L.; R. R. Grunert, R. F. Haff, J. W. McGahen, E. M. Neumayer, M. Paulshock, J. C. Watts, T.R. Wood, E. C. Hermann \& C. E. Hoffmann: Antiviral activity of 1-adamantanamine (amantadine). Science 144: 862 863, 1964 